\title{
Narrowing Transient Testing Pulse Widths to Enhance LWR RIA Experiment Design in the TREAT Facility
}

John D Bess, Nicolas E Woolstenhulme, Cliff B Davis, Louis M. Dusanter, Charles $P$ Folsom, James R Parry, Tate $\mathrm{H}$. Shorthill, Haihua Zhao

February 2019

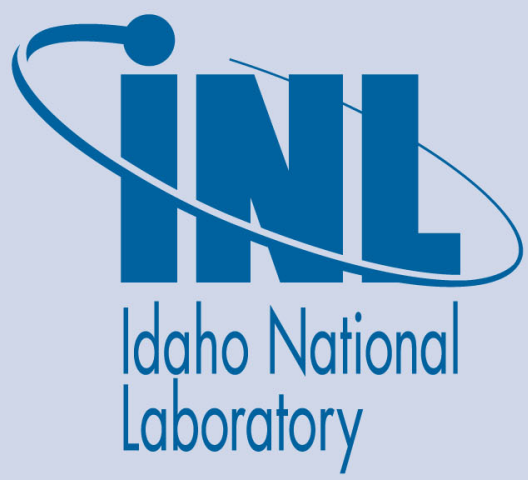

The INL is a U.S. Department of Energy National Laboratory operated by Battelle Energy Alliance 


\section{Narrowing Transient Testing Pulse Widths to Enhance LWR RIA Experiment Design in the TREAT Facility}

John D Bess, Nicolas E Woolstenhulme, Cliff B Davis, Louis M. Dusanter, Charles

P Folsom, James R Parry, Tate H. Shorthill, Haihua Zhao

February 2019

Idaho National Laboratory Idaho Falls, Idaho 83415

http://www.inl.gov

Prepared for the U.S. Department of Energy Office of Nuclear Energy Under DOE Idaho Operations Office

Contract DE-AC07-05ID14517 


\title{
Narrowing Transient Testing Pulse Widths to Enhance LWR RIA Experiment Design in the TREAT Facility
}

\author{
John D. Bess - ORCID: 0000-0002-4936-9103 - John.Bess@inl.gov
}

Nicolas E. Woolstenhulme - ORCID: 0000-0002-7881-3314 - Nicolas.Woolstenhulme@inl.gov

Cliff B. Davis - ORCID: none - Cliff.Davis@inl.gov

Louis M. Dusanter - ORCID: none - Louis.Dusanter@gmail.com

Charles P. Folsom - ORCID: 0000-0002-8242-8777 - Charles.Folsom@inl.gov

James R. Parry - ORCID: 0000-0003-2837-2626 - James.Parry@inl.gov

Tate H. Shorthill - ORCID: none - Tate.Shorthill@inl.gov

Haihua Zhao - ORCID: 0000-0002-8794-1027 - Zhao@kairospower.com

Idaho National Laboratory, 2525 N. Fremont Ave, Idaho Falls, Idaho 83415

Corresponding Author:

John D. Bess

Idaho National Laboratory, 2525 N. Fremont Ave, P.O. Box 1625, MS 3855, Idaho Falls, Idaho 83415

Phone: (208) 523-1766, Email: John.Bess@INL.gov

Total Number of Pages: 66

Total Number of Tables: 2

Total Number of Figures: 29 


\title{
Narrowing Transient Testing Pulse Widths to Enhance
}

\section{LWR RIA Experiment Design in the TREAT Facility}

\author{
John D. Bess, Nicolas E. Woolstenhulme, Cliff B. Davis, Louis M. Dusanter, \\ Charles P. Folsom, James R. Parry, Tate H. Shorthill, Haihua Zhao \\ Idaho National Laboratory, 2525 N. Fremont Ave, Idaho Falls, Idaho 83415
}

Abstract - The Transient Reactor Test (TREAT) Facility provided thousands of transient irradiations and plays a crucial role in nuclear-heated safety research. The facility's flexible design and multi-mission nature saw historic experiments for numerous reactor fuels and transient types but was never specifically adapted to address very-brief pulse transients akin to postulated Light Water Reactor (LWR) Reactivity Initiated Accidents (RIA). Since the behaviors of fuel under these conditions depends strongly on energy input duration and resulting cladding time/temperature response under pellet cladding mechanical interactions, this three-year project was conceived to investigate new pulse-narrowing capabilities. Kinetic models showed incremental improvements for minor facility enhancements including increased reactivity step insertions (to initiate the power pulse) and slightly-increased transient rod drive speed for pulse termination (“clipping”). Replacing peak fuel assemblies, repositioning non-transient control rods to hold down the "hot side" of the core, and balancing against required excess reactivity needs, the limiting fuel assembly power can be reduced by $\sim 20 \%$. This is a remarkable discovery of latent capability in TREAT, not only in enabling the subject capabilities for reduced pulse widths, but also significantly "uprating" the core's transient energy capacity. Incremental improvements can likely enhance TREAT's capability into BWR-relevant missions; briefer PWR pulse shapes can only be achieved with an advanced clipping system. Helium-3 $\left({ }^{3} \mathrm{He}\right)$ was 
found to offer the greatest benefits for clipping design and overall performance. A unique concept showed great promise for enabling a ${ }^{3} \mathrm{He}$-based system with a reasonable cost; this design concept will likely become the focal point of future work.

Keywords - Light Water Reactor, Pulse Widths, Reactivity Initiated Accidents, Transient Testing, TREAT

Highlights-

- LDRD established to enable TREAT support of LWR HZP-RIA testing.

- Kinetics studies indicated transient clipping techniques necessary to narrow pulse widths.

- Core power flattening techniques can increase available reactivity for transient testing.

- ${ }^{3} \mathrm{He}$ clipping necessary to support PWR HZP-RIA testing in TREAT.

- The primary focus of future work will explore ${ }^{3} \mathrm{He}$ system design and optimization. 


\section{Introduction}

This article provides a more thorough discussion of a paper presented at PHYSOR 2018, April 22-26, 2018, in Cancún, México, entitled “Optimization Options for Narrowing Transient Testing Pulse Widths Necessary to Enhance LWR RIA Simulations in the TREAT Facility" (Woolstenhulme, et al., 2018).

\subsection{Transient Reactor Test (TREAT) Facility}

The Transient Reactor Test (TREAT) Facility was constructed in the late 1950's (Freund et al., 1958) and provided thousands of transient irradiations before being placed in standby in 1994 (Wright 2015). More than two decades later, and following a successful effort to revitalize the facility, resumption of reactor operations at TREAT began in late 2017 and has since been undergoing restart testing and core characterization activities, in preparation to once again provide modern transient testing capabilities to address crucial nuclear fuel research data needs (Bumgardner 2015).

TREAT is an air-cooled reactor driven by a core of graphite blocks having a small concentration of dispersed uranium oxide. Columns of these graphite-fuel blocks are hermetically encapsulated in zirconium alloy sheet metal canisters. Aluminum-sheathed unfueled graphite blocks are attached to the top and bottom of each fuel column; forming a discrete fuel assembly with $\sim 1.2 \mathrm{~m}$ of active core length surrounded by $\sim 61 \mathrm{~cm}$ of graphite reflector. Along with control rod, experiment, and graphite reflector assemblies, these fuel assemblies are placed on a $19 \times 19$ grid plate providing 361 available positions, creating a configurable core that can be adjusted to suit particular nuclear parameters or experimental objectives. A few fuel assemblies are typically removed from the central core positions to create a cavity for experiments. 
Experiment assemblies are removed from or placed into the core through a slot in the reactor's upper rotating shield plug, handled outside the reactor using shielded casks, and stowed below grade in storage holes when not in use. TREAT experiment vehicles are typically self-contained assemblies with engineered capabilities to safely contain any hazards, support specimens/instrumentation, and provide the desired specimen boundary conditions (Woolstenhulme et al., 2014).

Four slots can be opened through the vertical concrete shield walls and permanent graphite reflector surrounding the above-grade core to provide various capabilities. Two slots are currently in use, one for a neutron radiography beam, and the other for a fuel motion monitoring system (commonly referred to as the hodoscope) capable of collecting spatially-resolved data for fast neutrons born in experiment specimens (De Volpi, et al., 1982 and Chichester, et al., 2015). An isometric overview of TREAT's primary features can be seen in Fig. 1. An overhead schematic of the TREAT facility is provided in Fig. 2. A more comprehensive description of TREAT characteristics and components can be read elsewhere (ANL/RAS 1972, Bess and DeHart 2015). 


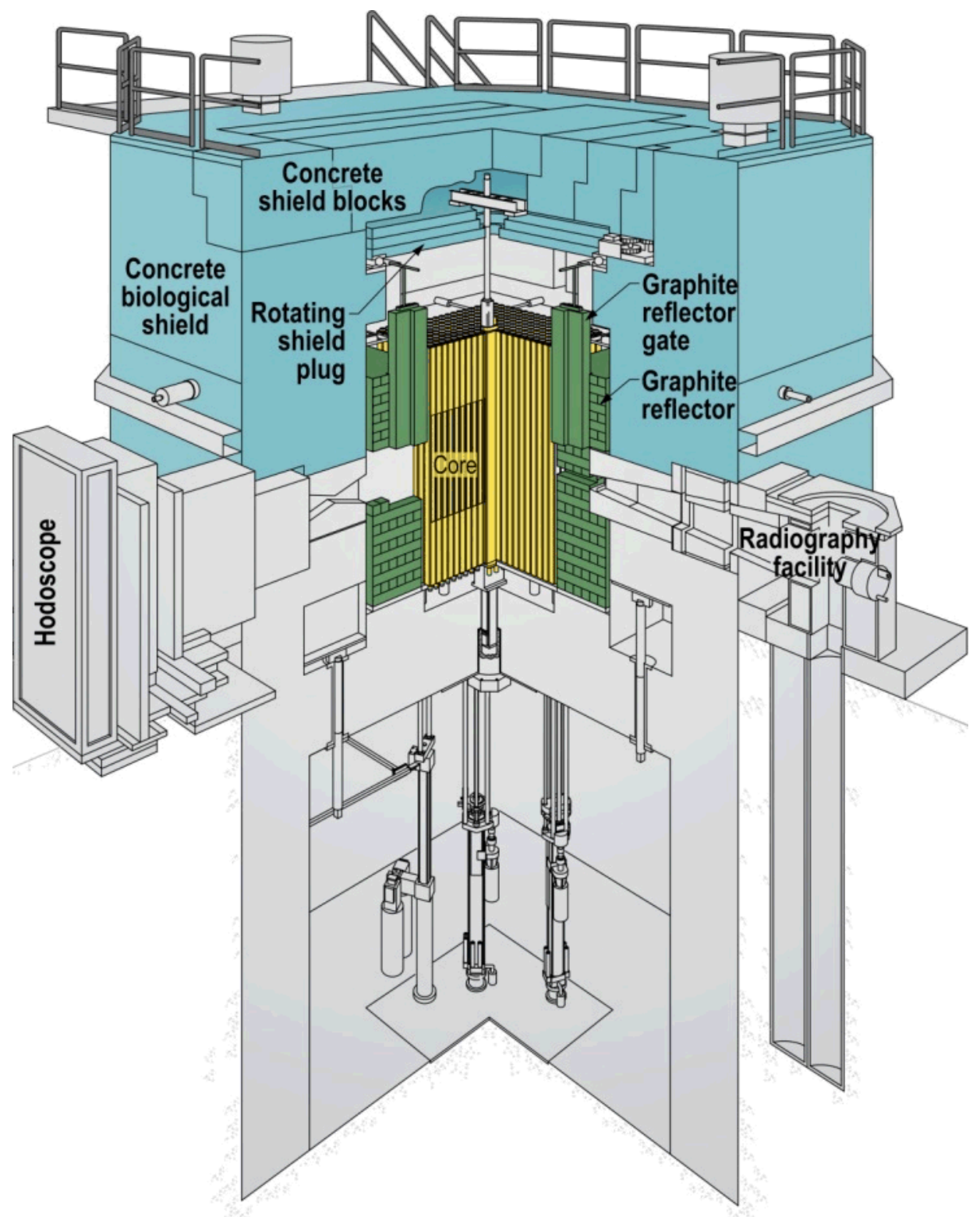

Fig. 1. Isometric Overview of TREAT Features, 3/4 Section View (Bess and DeHart 2015). 


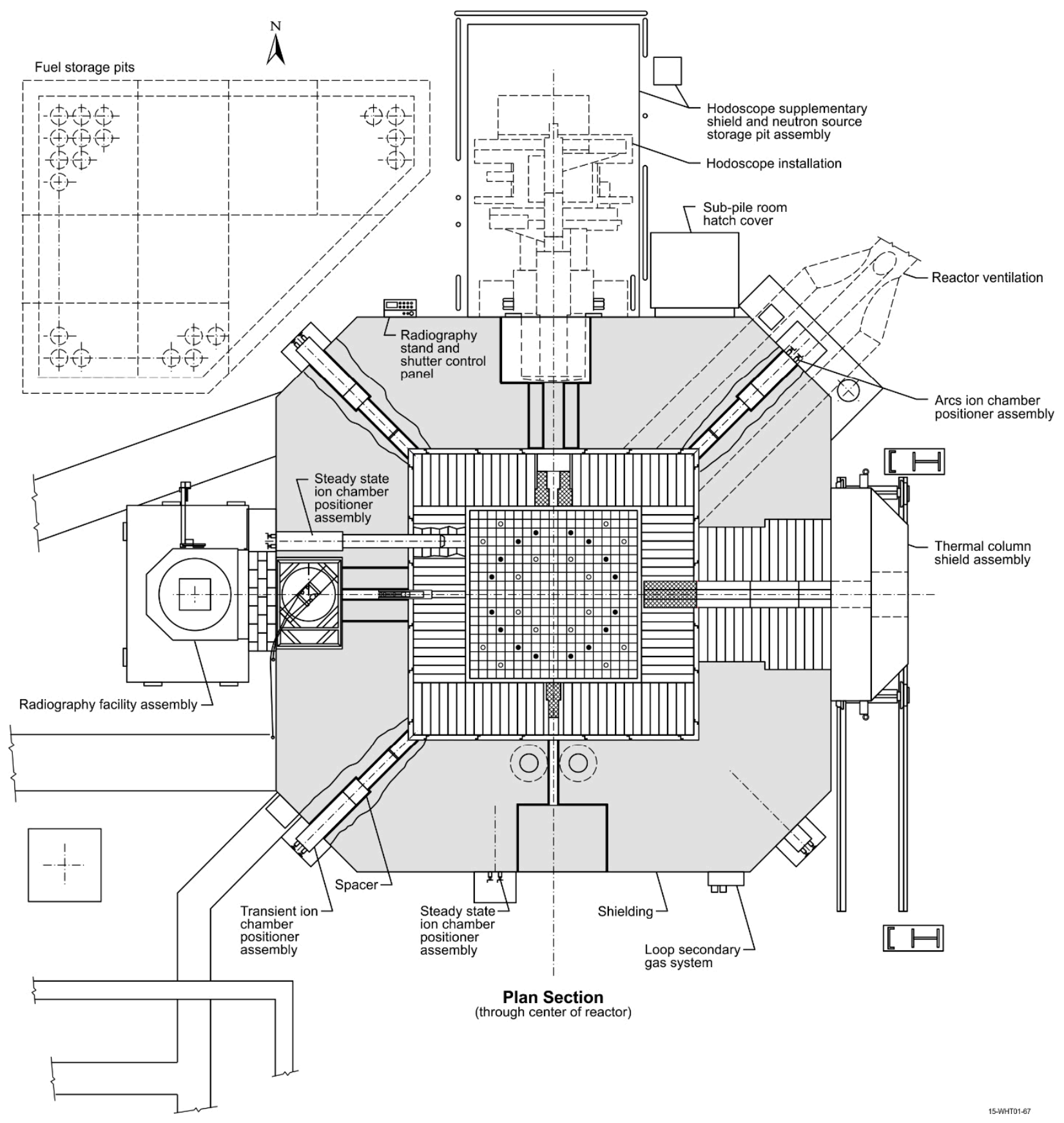

Fig. 2. Overhead Layout of Primary TREAT Facility Features. 
The evenly-distributed dilute concentration of uranium oxide in the fuel blocks provides that transient nuclear heating is distributed rapidly into the graphitic heat-sink/moderator to cause a neutron energy spectral shift with strong negative temperature feedback for safe self-limiting power excursions (MacFarlane et al., 1958). TREAT's air-cooling system is adequate for steady state operation at $120 \mathrm{~kW}$ thermal power, useful for physics measurements, isotope build-in (e.g. ${ }^{131}$ I) for follow-on tests, neutron radiography, and other system checkout operations. TREAT's true capability, however, lies in its transient operations. TREAT's fast-acting hydraulicallydriven transient control rods (see Fig. 3) couple with the Automatic Reactor Control System (ARCS) to leverage the primarily-graphite core's negative temperature feedback to enable unrivaled power shaping capability. More than just a pulse reactor, TREAT is a transient reactor where inherently-safe core physics, a nimble transient rod drive system, and a philosophy of continual facility improvement work together to enable flexible power maneuvers relevant to current-fleet nuclear plants, advanced reactors, and scientifically-valuable power shapes. TREAT's transients can be shaped to vary over several orders of magnitude in reactor power and transient duration; the precise shape being practically governed simply by the core energy capacity (currently $2500 \mathrm{MJ}$ ). ARCS can interface with experiment diagnostics instruments to enable feedback control and synchronization of experiment boundary conditions (nuclear, thermal hydraulic, etc.) Enhancements to core management/modeling methods and rapid negative reactivity insertion "clipping" systems can augment this capability for transient capabilities transcending what is conventionally associated with graphite-based reactors. 


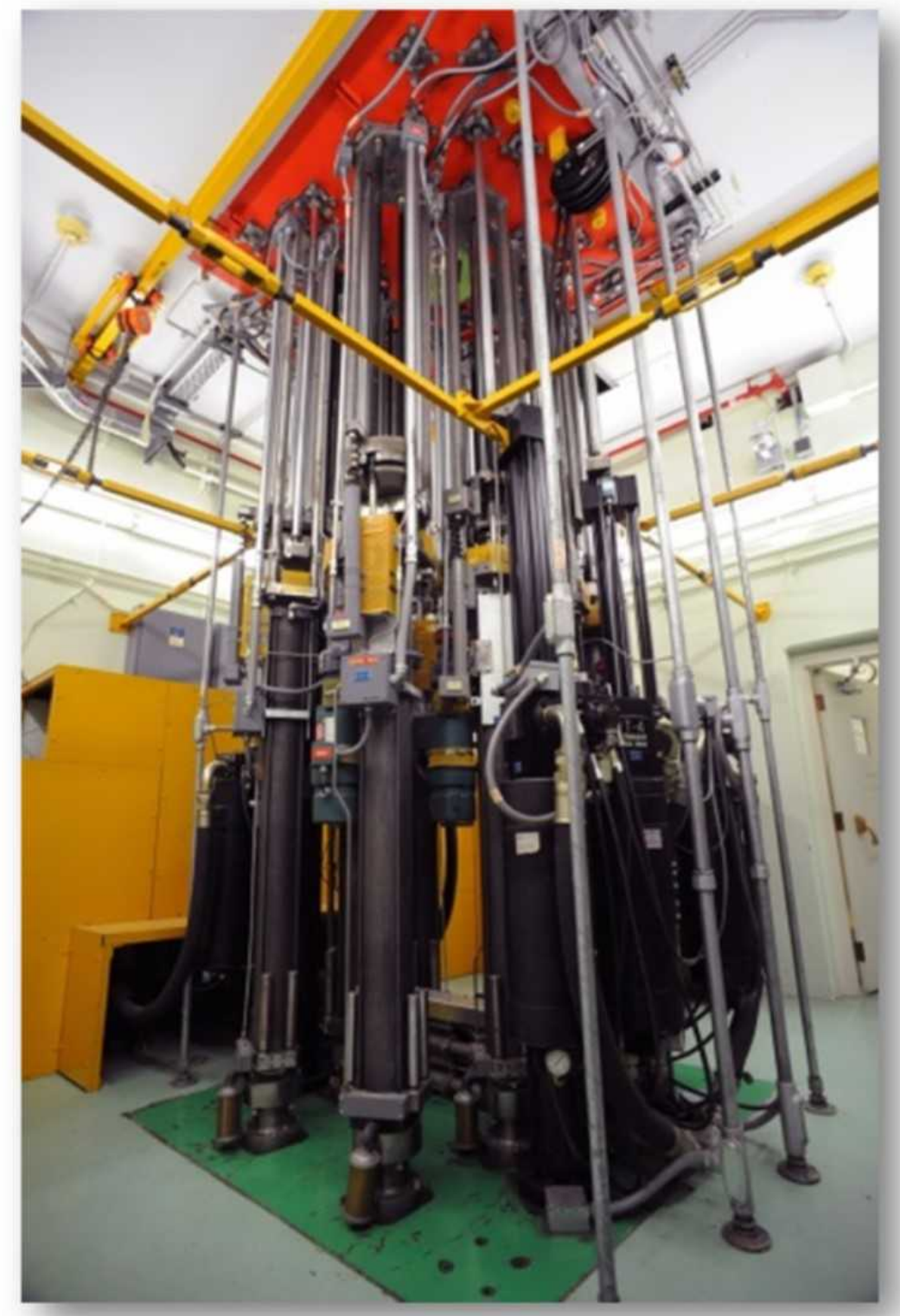

Fig. 3. TREAT Control Rod Drive System Viewed from Subpile Room. 


\subsection{Transient Testing to Support LWR Accident Simulations}

In general, in-pile irradiations can be categorized, or designed, for either steady-state or transient irradiations. Steady-state irradiations typically employ material test reactors with sufficient capability to accumulate nuclear heating and damage within a specific test environment, possibly with online data monitoring, for durations lasting months to years. Transient irradiations make use of transient test reactors where irradiation conditions last for minutes, seconds, or even less than a second. Most test reactors operate steady-state with limited transient capabilities. The combination of test reactors such as the Advanced Test Reactor (ATR) and TREAT can be utilized to maximize testing conditions with both steady-state and transient testing capabilities.

Steady-state irradiations are usually performed to reveal performance phenomena and/or limitations of the fuels or materials being used in nuclear plants during normal operations. As such, these irradiations serve to develop data supporting the economics of fuel applications. Transient testing is typically thought of as the study of nuclear fuels and materials under events that are brief in duration or changing in instantaneous conditions. Transient testing often focuses upon generating data to support safety or regulatory needs, and in many cases, a quintessential component supporting advanced concepts and licensure of novel technologies. These conditions include myriad scenarios such as postulated off-normal, accidental, and upset conditions in nuclear reactors (Woolstenhulme, et al., 2016a). Both irradiation types provide data useful for the validation of predictive methods and extension of the knowledge and understanding of nuclear fuels and materials. Modern transient test experimentation design will serve to validate advanced modeling and simulation techniques (DeHart, et al., 2016). 
Among the transient testing scenarios, power-cooling mismatch conditions (see Fig. 4) can challenge the integrity of fuel materials; making them the primary subject of nuclear fuel safety research. Some scenarios are slow enough in duration that the salient performance phenomena can be exhibited in steady-state nuclear reactors, such as the ATR (Grover, et al., 2010, Knudson and Rempe 2012). Other scenarios are loosely coupled enough to irradiation effects from neutrons and gammas that they can be simulated to some degree with out-of-pile tests, such as furnace tests in the Fuel Accident Condition Simulator (FACS) (Demkowicz, et al., 2012). In-pile nuclear-heated transient testing, rather than out-of-pile testing, is typically required in scenarios where rapid power excursions, representative distributions of specimen heat generation, and coupled irradiation effects are needed to accurately represent behavior. Furthermore, these scenarios must be simulated in transient reactors specially adapted to provide prototypic environmental and experimental conditions.

TREAT's brilliantly basic design, augmented by decades of incremental facility upgrades, create an extraordinary capability for nuclear-heated transient testing. TREAT's power maneuvering capability, when paired with experiment vehicles that provide specimen boundary conditions, complemented by in-situ instrumentation, and collocated with post-transient examination facilities, produce a full capability package able to address data needs for practically any reactor type or accident category. Example transient shapes that TREAT can currently provide are shown in Fig. 5 through Fig. 9. Two major categories of TREAT transients are exponential or peaked bursts (natural) and shaped power bursts (shaped), where a flat top transient is a shaped transient where a constant elevated core power is maintained for a period of time longer than encountered with a typical natural burst. Exponential bursts are temperaturelimited or rod-and-temperature-limited excursions; the latter of which the control rods are 
dropped to clip the transient short before the temperature limit is reached or to limit the energy deposited on the tail-end of the transient. Shaped power bursts are produced by a step insertion of reactivity followed by reactivity insertion or removal at rates required to produce the desired burst shape; delayed neutron effects and the power history of a given transient impact the maximum energy available during a shaped transient. Up to $120 \mathrm{~kW}$ of thermal power can be provided during steady-state operation of TREAT (ANL/RAS 1972). The peak fuel and clad temperature have a limiting control setting (LCS) of $\leq 600^{\circ} \mathrm{C}(\sim 873 \mathrm{~K})$ during normal TREAT transient operations to maximize fuel lifetime by minimizing oxidation of the Zircaloy-3 cladding, maintaining clad integrity (TS-420 2017, SAR-420 2017). During typical transient tests the fueled region of the core is expected to be between room temperature, $\sim 300 \mathrm{~K}$, and 873 K. The amount of excess reactivity loaded into a given core/experiment configuration is limited to prevent transient excursions at higher temperatures. The characterization transient measurements performed for the current core configuration determined that a step insertion of approximately $4.6 \% \Delta \mathrm{k} / \mathrm{k}$ is needed to achieve the temperature limit of $600{ }^{\circ} \mathrm{C}$, and approximately $5.9 \% \Delta \mathrm{k} / \mathrm{k}$ to reach a temperature of $820^{\circ} \mathrm{C}$. 


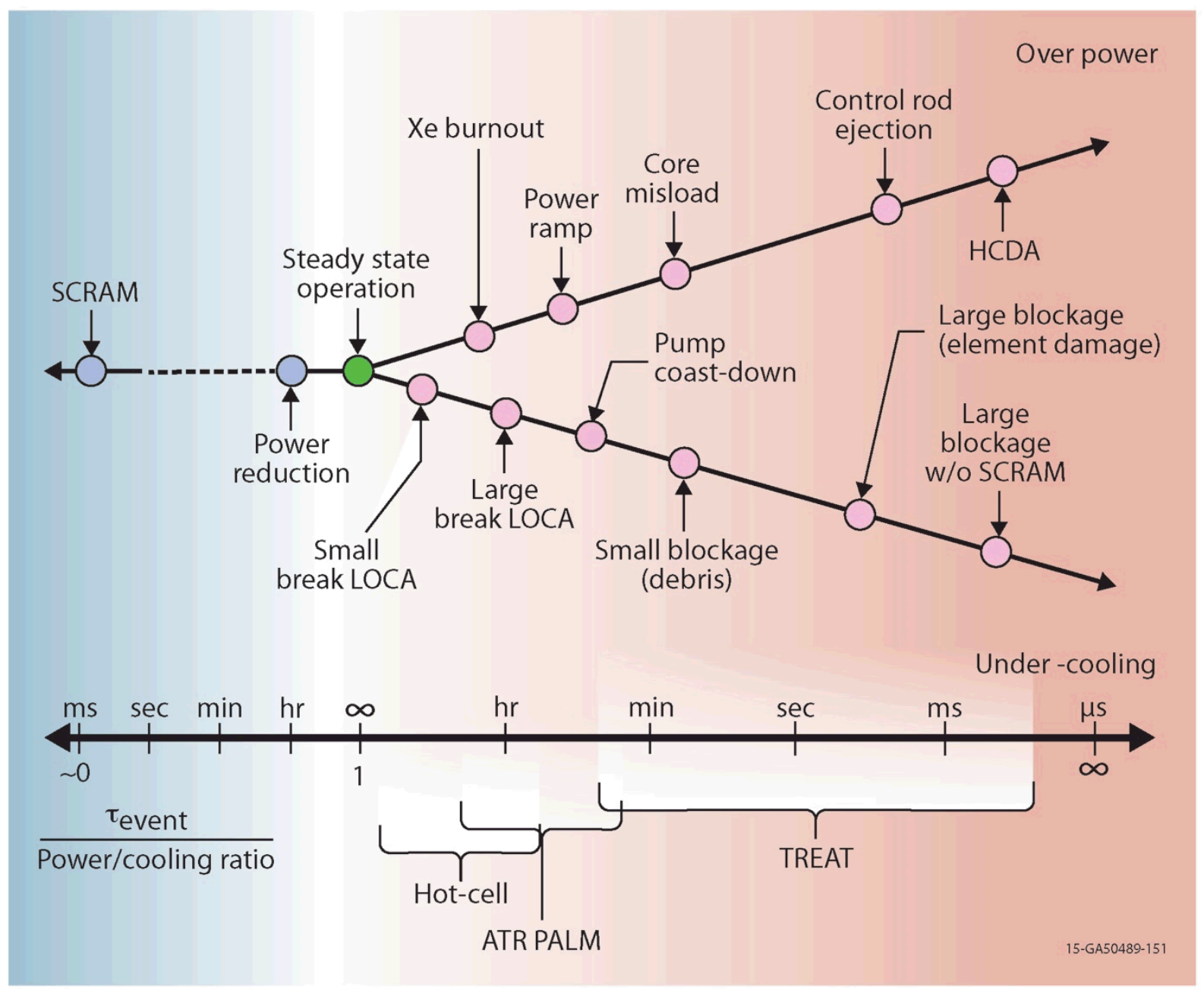

Fig. 4. Power/Cooling Mismatch Conditions. 


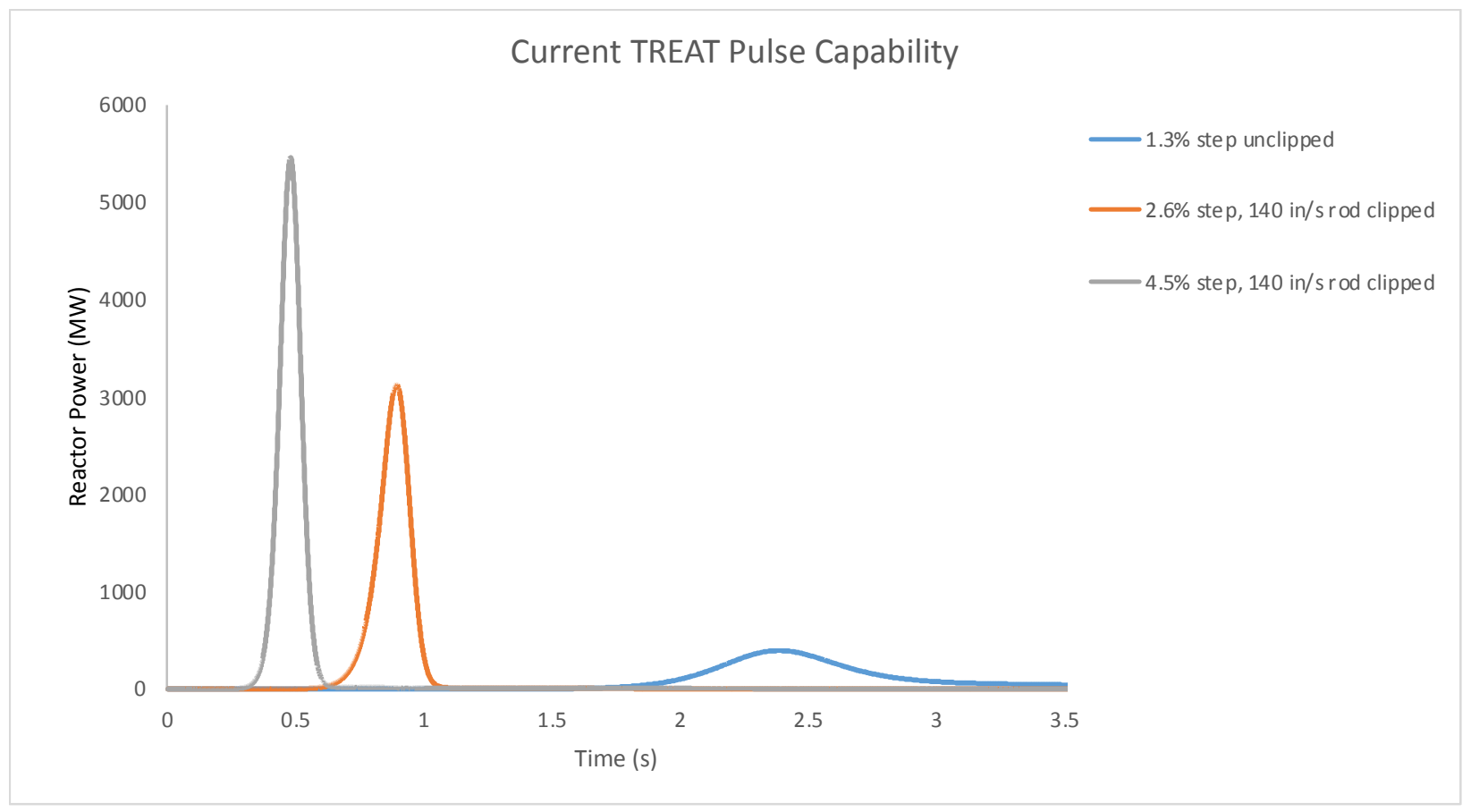

Fig. 5. Current TREAT Pulse Capability. 


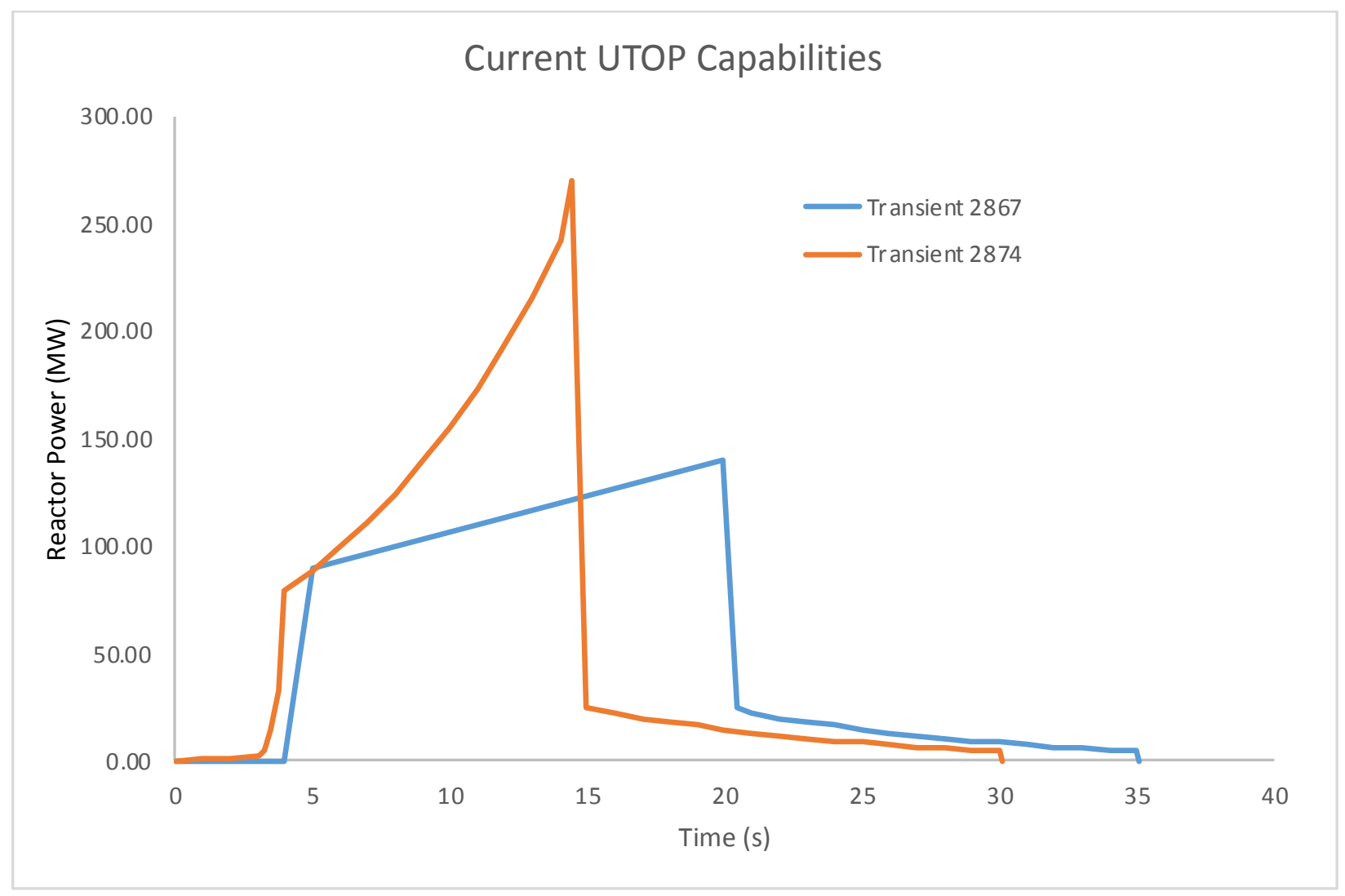

Fig. 6. Current TREAT Unprotected Transient Over Power (UTOP) Capabilities. 


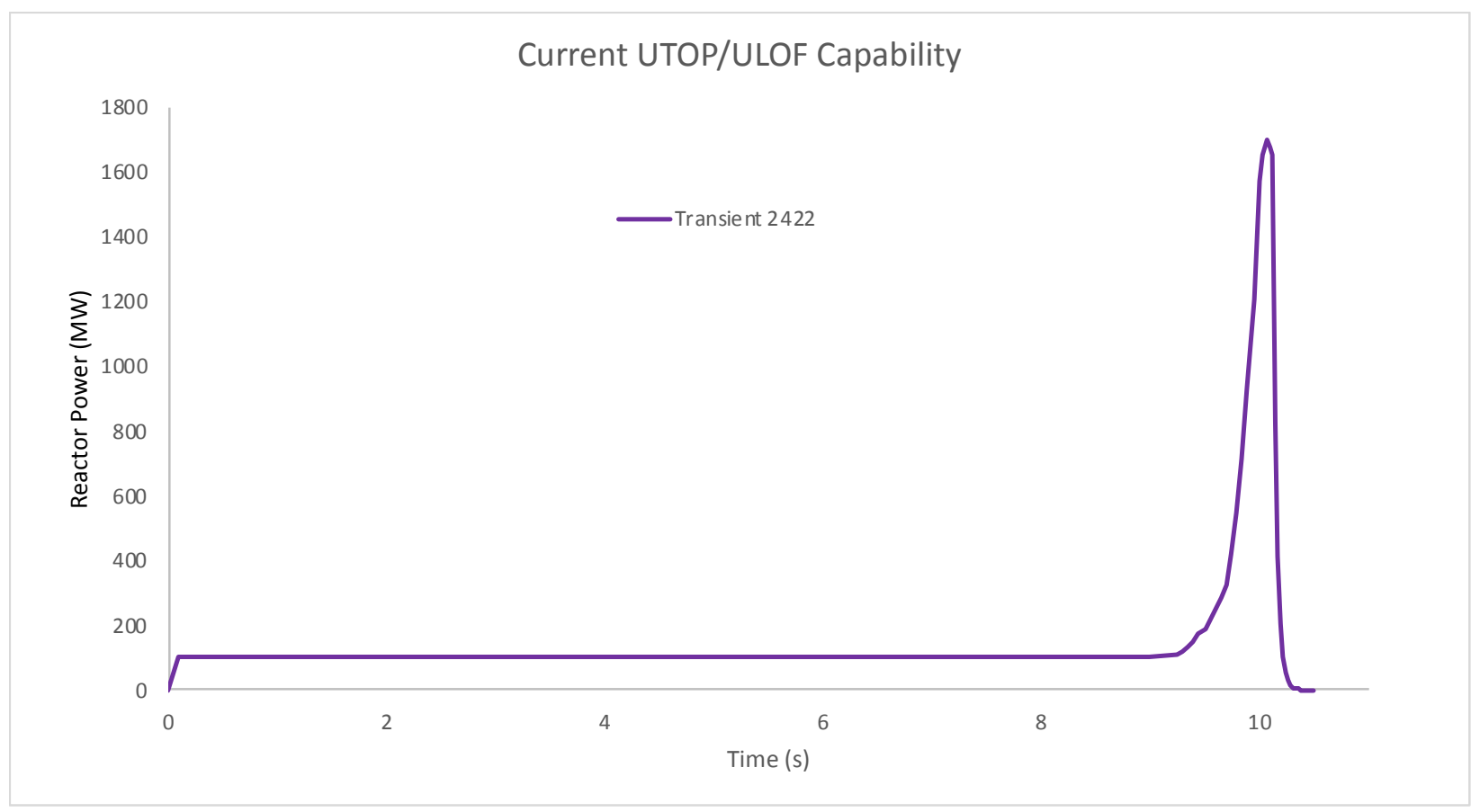

Fig. 7. Current TREAT UTOP and Unprotected Loss of Flow (ULOF) Capability. 
TREAT LOCA Capability

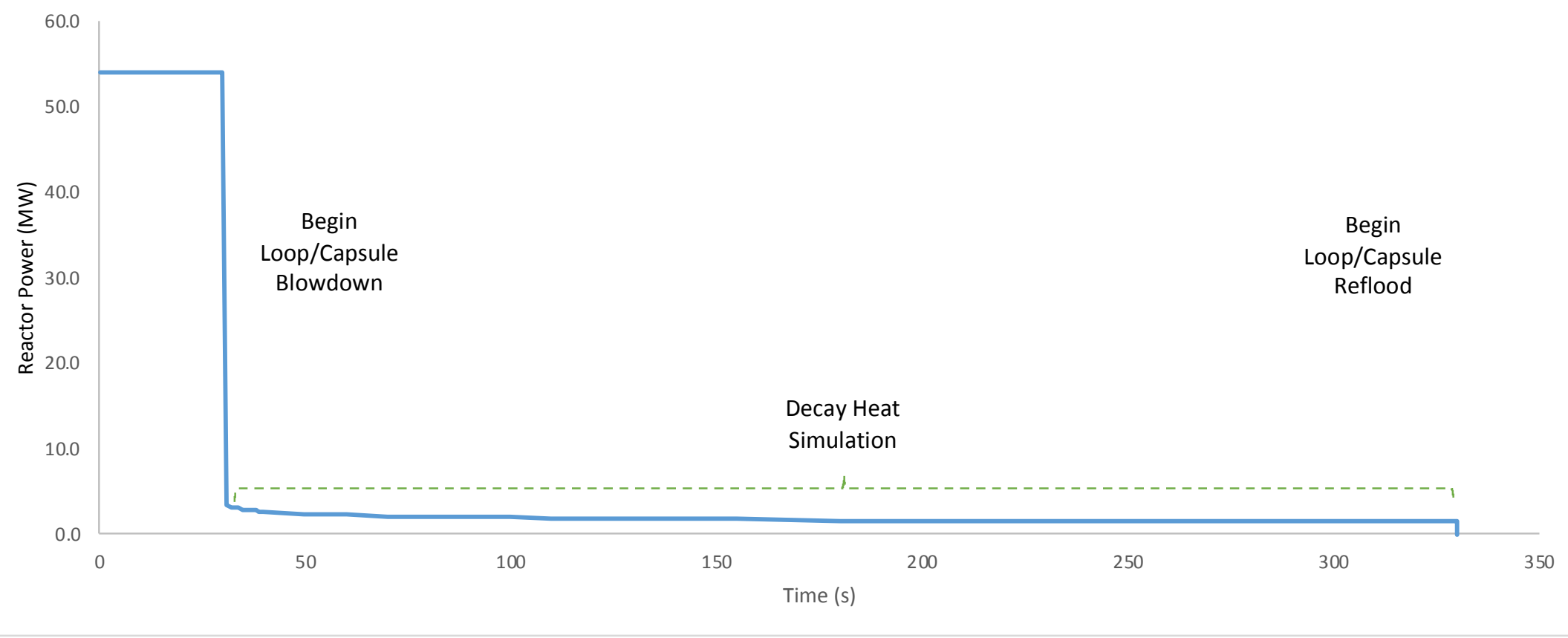

Fig. 8. Current TREAT Loss of Coolant Accident (LOCA) Capability. 


\section{Current TREAT Flattop Capability}

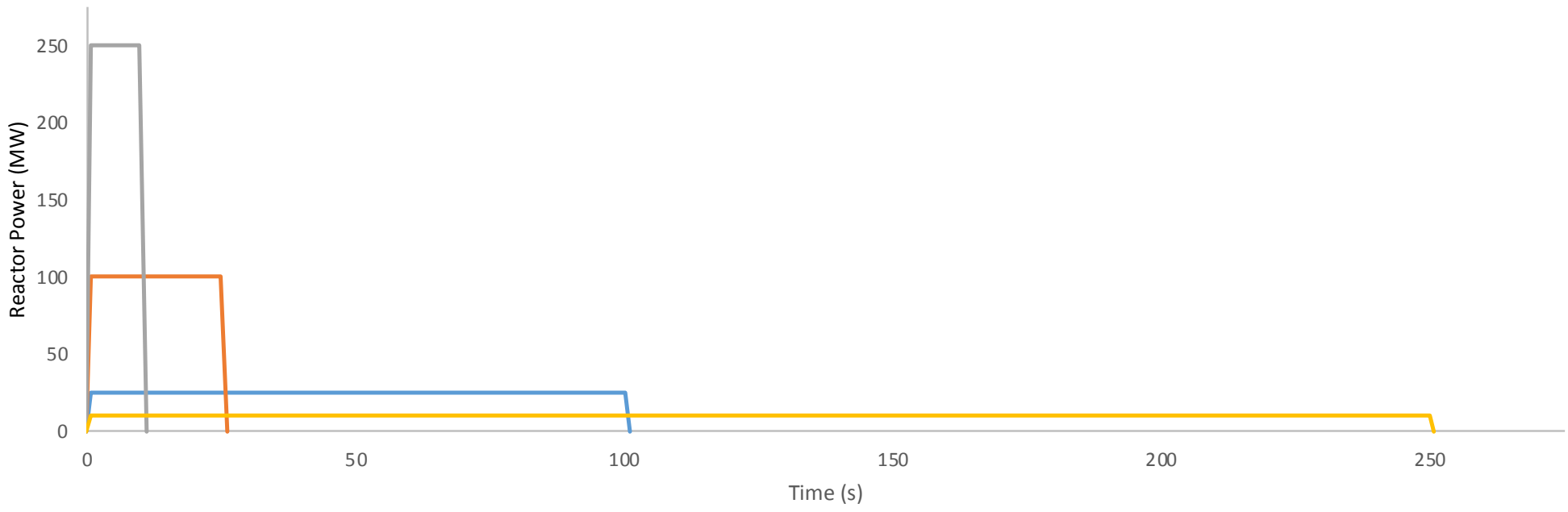

Fig. 9. Current TREAT Flattop Capability. 
TREAT's versatile design and multi-mission nature saw historic experiments for numerous reactor fuels and transient types. Resumption of transient testing in TREAT includes many new missions, such as metal-cooled advanced reactor fuels, nuclear thermal propulsion, and other advanced reactor designs. The Accident Tolerant Fuel (ATF) campaign (Carmack, et al., 2013) has transient testing needs similar to those for conventional Light Water Reactors (LWRs). While TREAT stands as one of the most capable reactors for transient testing, it was primarily operated to support domestic sodium fast reactor programs and was never specifically adapted to address very-brief pulse transients akin to postulated LWR Hot Zero Power Reactivity Initiated Accidents (HZP-RIA). HZP-RIAs are postulated to be initiated by ejection of control elements (blades, rods, etc.) from an LWR core when the reactor is preheated to operational inlet temperatures, but not yet producing fission power; the result would be a brief nuclear power excursion where rapid fuel pellet thermal expansion could drive cladding failure through mechanical interaction.

A simple measure of RIA pulse width is the Full-Width at Half Maximum (FWHM). Pulse width is a critical parameter as it affects the timing of pellet-to-cladding heat transfer, and the resulting temperature-dependent mechanical properties, along with affecting strain rates during the mechanical interaction. Recent simulations suggest that peak cladding hoop stress can be more than doubled in a pulse $30 \mathrm{~ms}$ versus a slightly wider pulse $90 \mathrm{~ms}$ FWHM (Folsom, et al., 2016). Transient test experiments with excessively narrow pulse widths are undesirable because they are likely to indicate inaccurately low failure thresholds; resulting in unnecessary limitations on LWR plant design and operations. Similarly, tests with excessively wide pulses are undesirable as they could produce optimistic indications of fuel performance that may not be 
accepted as the regulatory basis for operating LWR plants. An RIA power pulse schematic showing the coupled relationship between power, energy deposition, and radial average peak fuel enthalpy is shown in Fig. 10 (Yang 2002). Transient test experiments providing proper prototypic environments and pulse widths would most adequately represent the desired accident responses being assessed for LWR fuels.

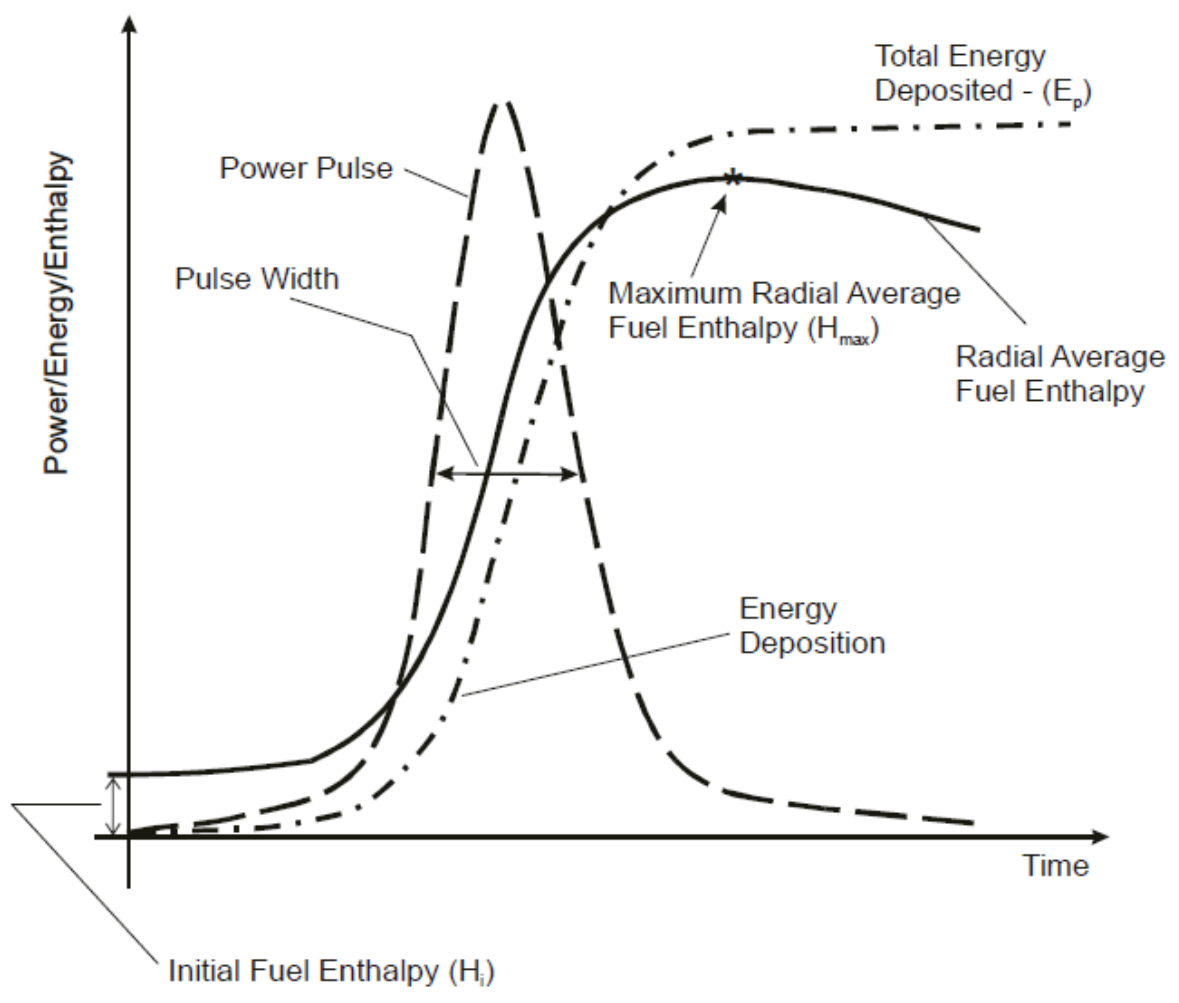

Fig. 10. RIA Power Pulse Schematic Showing the Relationship between Power, Energy Deposition, and Radial Average Peak Fuel Enthalpy (Yang 2002).

There are just a few transient test reactors in the world capable of depositing adequate energy into irradiated fuel specimens within the $30-100 \mathrm{~ms}$ FWHM range. A comparison of transient conditions for several contemporary reactors is shown in Fig. 11. The comparison 
includes conventional, clipped, and advanced helium-3 $\left({ }^{3} \mathrm{He}\right)$ clipping conditions for TREAT, Pressurized Water Reactors (PWRs) and Boiling Water Reactors (BWRs) (OECD NEA 2010), the French CABRI reactor (Cabrillat, et al., 2003), Japanese Nuclear Safety Research Reactor (NSRR) (Fuketa, et al., 2006), the United States (US) Annual Core Research Reactor (ACRR) (Royl, et al., 1987), Impulse Graphite Reactor (IGR) in Kazakhstan (Payot, et al., 2017), and the US Power Burst Facility (PBF) (Petti, et al., 1994). While PBF represents the most likely candidate for LWR accident analysis, it was unfortunately decommissioned and is no longer available to support LWR transient testing; it is provided as a comparison with currently available test reactors. Modern LWR transient testing capabilities are underway including a recently-commissioned LWR loop at CABRI (Hudelot, et al., 2016) and forthcoming LWRenvironment capsules/loops for TREAT (Woolstenhulme, et al., 2016b). While CABRI's innate FWHM is approximately $10 \mathrm{~ms}$, it can be "stretched" by continuing to insert reactivity after the initial step-up to achieve $20-80 \mathrm{~ms}$ (Clamens, et al., 2016). TREAT's innate FWHM, depending on the total core energy deposited, is greater than $100 \mathrm{~ms}$, but it can be clipped by rapid insertion of control rods to be slightly less than $100 \mathrm{~ms}$ (Crawford, et al., 1998). The overlap between TREAT and CABRI is narrow, and perhaps nonexistent, depending on the desired pulse energy. To enhance the overlap between these complimentary facilities, and to enhance TREAT's relevance for LWR testing in general, it will be necessary to modify TREAT such that it can achieve a shorter FWHM. 


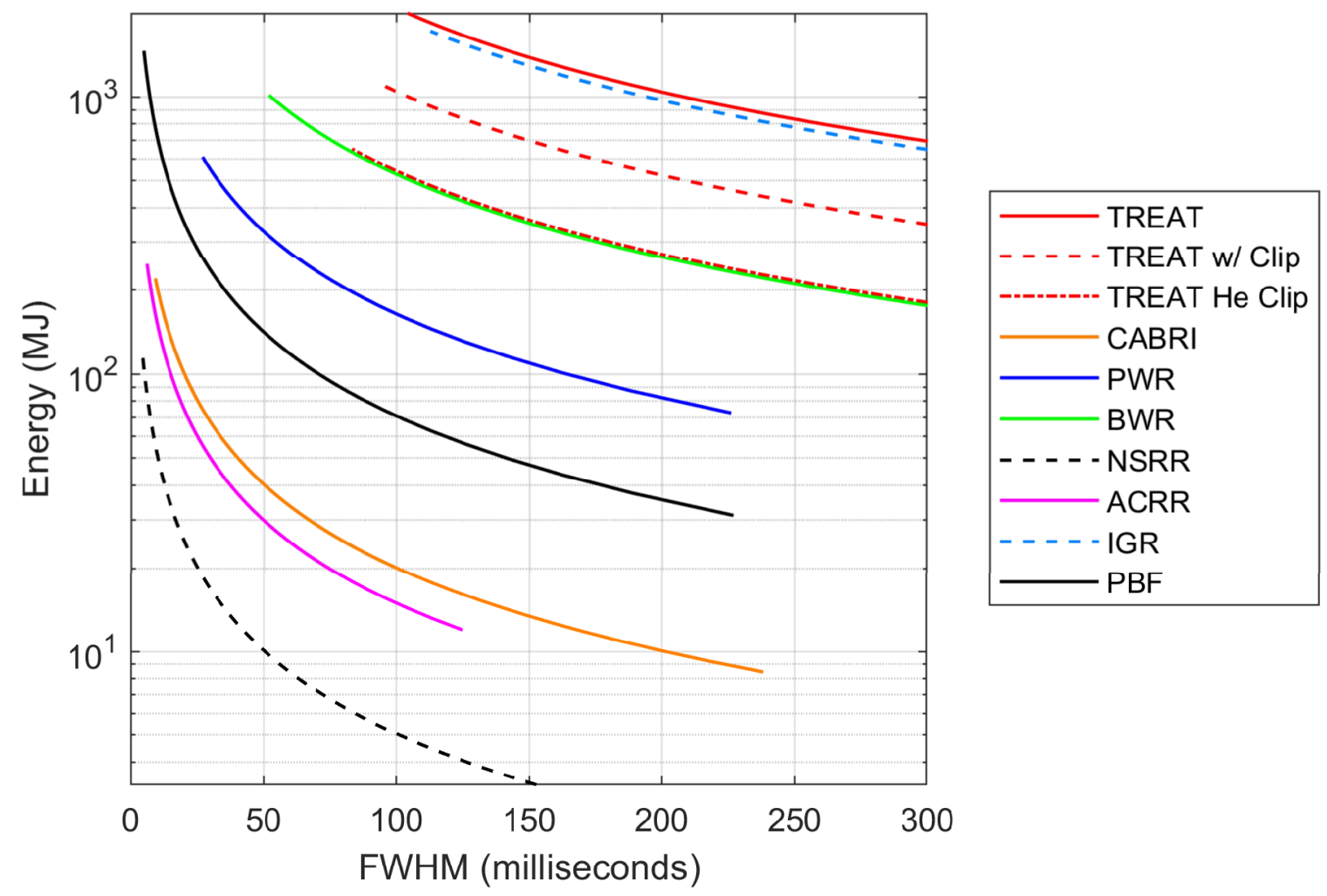

Fig. 11. Comparison of Contemporary Reactor Transient Conditions.

\subsection{Laboratory Directed Research and Development (LDRD) Project Purpose}

TREAT is currently capable of performing transients to achieve pulse's whose FWHM duration is $<100 \mathrm{~ms}$, and perhaps as narrow as $72 \mathrm{~ms}$ (Crawford, et al., 1998), but not squarely in the desired range of $25 \mathrm{~ms}$ to 65 and $45 \mathrm{~ms}$ to $75 \mathrm{~ms}$ FWHM required for simulating HZPRIAs for PWR and BWR, respectively (OECD NEA 2010). Since the behaviors of fuel under these conditions depends strongly on energy input duration and resulting cladding time/temperature response under Pellet Cladding Mechanical Interactions (PCMI), this project was conceived and funded under Laboratory Directed Research and Development (LDRD, No. 17A1-024FP) to develop pulse-narrowing capabilities for the future TREAT. This project is an 
engineering-based research effort to evaluate and optimize strategies to enable the minimization of TREAT FWHM capabilities to support LWR accident testing.

While narrowing TREAT's pulse width will be vital for supporting future LWR HZPRIA testing, it will also be important that any modifications do not diminish TREAT's current capabilities since its innate pulse width will be well-suited to support hot full power RIA tests. Additionally, TREAT's remarkable capability to shape transients, such as ramps, decays, flattops, and combinations thereof, must all be retained to support transient testing of sodium fast reactors, other LWR scenarios types, and yet-to-be-envisioned nuclear science missions. Similarly, any modifications to TREAT must not interfere with TREAT's ex-core data capabilities, such as the hodoscope and neutron radiography. In short, the results of this work must further enhance, without diminishing, the transient testing capabilities of TREAT.

The present work summarizes the accomplishments of this LDRD project during its first of a planned three-year effort. The technical work performed to date addressed the first two of the three main focus areas of this LDRD:

1. Developing strategies to tolerate increased step insertions.

2. Conceptualizing systems for enhanced clipping.

3. Evaluating these options against hypothesized LWR RIAs in order to assess their effectiveness and enable selection of the preferred approach.

Potential concepts will be evaluated, and the identification of the most promising design/strategy will lead future efforts towards its development and implementation within TREAT. 


\section{Investigated Concepts}

\subsection{Kinetics Studies}

The effects of various parameters on a power excursion in TREAT were studied in order to reduce the pulse width and make it more prototypical of a commercial PWR. A RELAP5-3D (INL 2018) point kinetics model of TREAT was used in this study (Davis 2016). One of the historic experiment tests used to validate the RELAP5-3D model was TREAT Transient Test 2857. This test was a natural shaped transient that was initiated by a near step reactivity insertion of $3.87 \% \Delta \mathrm{k} / \mathrm{k}$, with the log power measurement of the control computer was judged to be the best available measurement. The data from the log power measurement were used to validate the RELAP5-3D model for the calculation of pulse width based on the FWHM power. As shown in Table 1, RELAP5-3D provided reasonable calculations of maximum power, energy deposition, and pulse width. The calculated pulse width was about $4 \%$ greater than the measured value.

Table 1. Pulse Width Validation Results for TREAT Transient Test 2857.

\begin{tabular}{|cccc|}
\hline Data Source & $\begin{array}{c}\text { Maximum } \\
\text { Power } \\
\text { (MW) }\end{array}$ & $\begin{array}{c}\text { Energy } \\
\text { Deposition } \\
\text { (MJ) }\end{array}$ & $\begin{array}{c}\text { FWHM } \\
\text { (s) }\end{array}$ \\
\hline Measured & 12,030 & 2,120 & 0.119 \\
RELAP5-3D & 11,732 & 2,141 & 0.124 \\
\hline
\end{tabular}

The RELAP5-3D model was used to investigate the effects of various parameters on pulse width. The parameters that were investigated included the magnitude of the step reactivity insertion that initiated the power excursion, the speed at which negative reactivity can be inserted during the transient, and the total power peaking factor in the core. The initial temperature and power of the core were assumed to be $25{ }^{\circ} \mathrm{C}$ and $50 \mathrm{~W}$ in all of the calculations. The M8 
feedback table described in Davis 2016 was used, which is the reactivity feedback table developed supporting the M8CAL experiment series (Robinson and Bauer 1994). The maximum peaking factor in the core was varied between 1.60 and 1.82 . Table 2 summarizes the various cases that were investigated. Calculated results include energy deposition, maximum fuel temperature, and pulse width. 
Table 2. Summary of RELAP5-3D Kinetics Simulations of TREAT Transient Cases.

\begin{tabular}{|c|c|c|c|c|c|c|}
\hline \multirow{2}{*}{ Case } & \multicolumn{2}{|c|}{ Reactivity Clipping Time } & & \multicolumn{3}{|c|}{ Maximum } \\
\hline & $\begin{array}{c}\text { Insertion } \\
(\Delta \mathrm{k} / \mathrm{k})\end{array}$ & $\begin{array}{l}\text { / Speed } \\
\text { (s) / (in/s) }\end{array}$ & $\begin{array}{l}\text { Peaking } \\
\text { Factor }\end{array}$ & $\begin{array}{l}\text { Energy } \\
\text { Deposition } \\
\text { (MJ) }\end{array}$ & $\begin{array}{l}\text { Fuel } \\
\text { Temperature } \\
\left({ }^{\circ} \mathrm{C}\right)\end{array}$ & $\begin{array}{l}\text { FWHM } \\
(\mathrm{s})\end{array}$ \\
\hline 1 & 0.040 & $\mathrm{NA} / \mathrm{NA}$ & 1.82 & 2266 & 529 & 0.119 \\
\hline 2 & 0.043 & NA / NA & 1.82 & 2525 & 575 & 0.1103 \\
\hline 3 & 0.046 & NA / NA & 1.82 & 2799 & 621 & 0.1027 \\
\hline 4 & 0.049 & NA / NA & 1.82 & 3086 & 668 & 0.0963 \\
\hline 5 & 0.052 & NA / NA & 1.82 & 3388 & 717 & 0.0909 \\
\hline 6 & 0.055 & NA / NA & 1.82 & 3704 & 766 & 0.0862 \\
\hline 7 & 0.058 & NA / NA & 1.82 & 4035 & 816 & 0.0821 \\
\hline 8 & 0.040 & NA / NA & 1.60 & 2266 & 480 & 0.1192 \\
\hline 9 & 0.043 & NA / NA & 1.60 & 2525 & 521 & 0.1103 \\
\hline 10 & 0.046 & NA / NA & 1.60 & 2799 & 563 & 0.1027 \\
\hline 11 & 0.049 & NA / NA & 1.60 & 3086 & 607 & 0.0963 \\
\hline 12 & 0.052 & NA / NA & 1.60 & 3388 & 651 & 0.0909 \\
\hline 13 & 0.055 & NA / NA & 1.60 & 3704 & 696 & 0.0862 \\
\hline 14 & 0.058 & NA / NA & 1.60 & 4035 & 742 & 0.0821 \\
\hline 15 & 0.013 & NA / NA & 1.82 & 500 & 173 & 0.5675 \\
\hline 16 & 0.026 & $0.845 / 140$ & 1.82 & 500 & 173 & 0.1327 \\
\hline 17 & 0.045 & $0.364 / 140$ & 1.82 & 627 & 203 & 0.0954 \\
\hline 18 & 0.045 & $0.392 / 200$ & 1.82 & 626 & 203 & 0.0837 \\
\hline 19 & 0.045 & $0.405 / 250$ & 1.82 & 619 & 202 & 0.0771 \\
\hline 20 & 0.045 & $0.455 /{ }^{3} \mathrm{He}$ & 1.82 & 627 & 203 & 0.0458 \\
\hline 21 & 0.051 & $0.387 /{ }^{3} \mathrm{He}$ & 1.82 & 624 & 203 & 0.04 \\
\hline
\end{tabular}


Cases 1 through 7 investigated the effects of the magnitude of the step reactivity insertion that initiated the transient. The reactor power was allowed to respond naturally to the reactivity insertion and the reactor was shut down via thermal feedback. No clipping was assumed to occur. The pulse width decreases as the magnitude of the initial reactivity insertion increases. However, the energy deposition, which corresponds to the integral of the reactor power up to $60 \mathrm{~s}$ after the start of the transient, and the maximum fuel temperature increases as the initial reactivity insertion increases.

Flattening the core power distribution reduces the total peaking factor, allows a larger step insertion to obtain a given maximum fuel temperature, and therefore results in a reduction in the pulse width. Reducing the total peaking factor in the core from 1.82 to 1.60 reduced the pulse width by about $0.009 \mathrm{~s}$ at a maximum fuel temperature of $600{ }^{\circ} \mathrm{C}$. The effect of the total peaking factor at other fuel temperatures can be obtained by interpolation of the results shown in Table 2 for Cases 8 through 14 . The maximum fuel temperature in TREAT is currently limited to less than $600{ }^{\circ} \mathrm{C}$ and the minimum reactor period is limited to $0.023 \mathrm{~s}$ during natural shaped transients. The calculated results indicate that both the maximum temperature and minimum period criteria will be violated once the initial reactivity insertion exceeds about $4.6 \% \Delta \mathrm{k} / \mathrm{k}$. Thus, increasing the reactivity insertion above about $0.046 \% \Delta \mathrm{k} / \mathrm{k}$ would require changes to the current safety basis. Even then, increasing the step insertion does not reduce the pulse width to the desired value.

Figure 12 shows the reactor power from Cases 15 and 16, which were initiated by step reactivity insertions of $1.3 \% \Delta \mathrm{k} / \mathrm{k}$ and $2.6 \% \Delta \mathrm{k} / \mathrm{k}$, respectively. In Case 15 , the reactor power was allowed to respond naturally to the reactivity insertion and the reactor was shut down via thermal feedback. In Case 16, the transient rods were inserted beginning at $0.845 \mathrm{~s}$ at a speed of 
$140 \mathrm{in} . / \mathrm{s}(3.556 \mathrm{~m} / \mathrm{s})$, which is TREAT's current maximum transient rod speed capability. With these parameters, the total energy deposition in the core at $60 \mathrm{~s}$ was $500 \mathrm{MJ}$ in both cases.

Clipping greatly reduced the pulse width, with the FWHM value decreasing from $0.5675 \mathrm{~s}$ in Case 15 to $0.1327 \mathrm{~s}$ in Case 16.

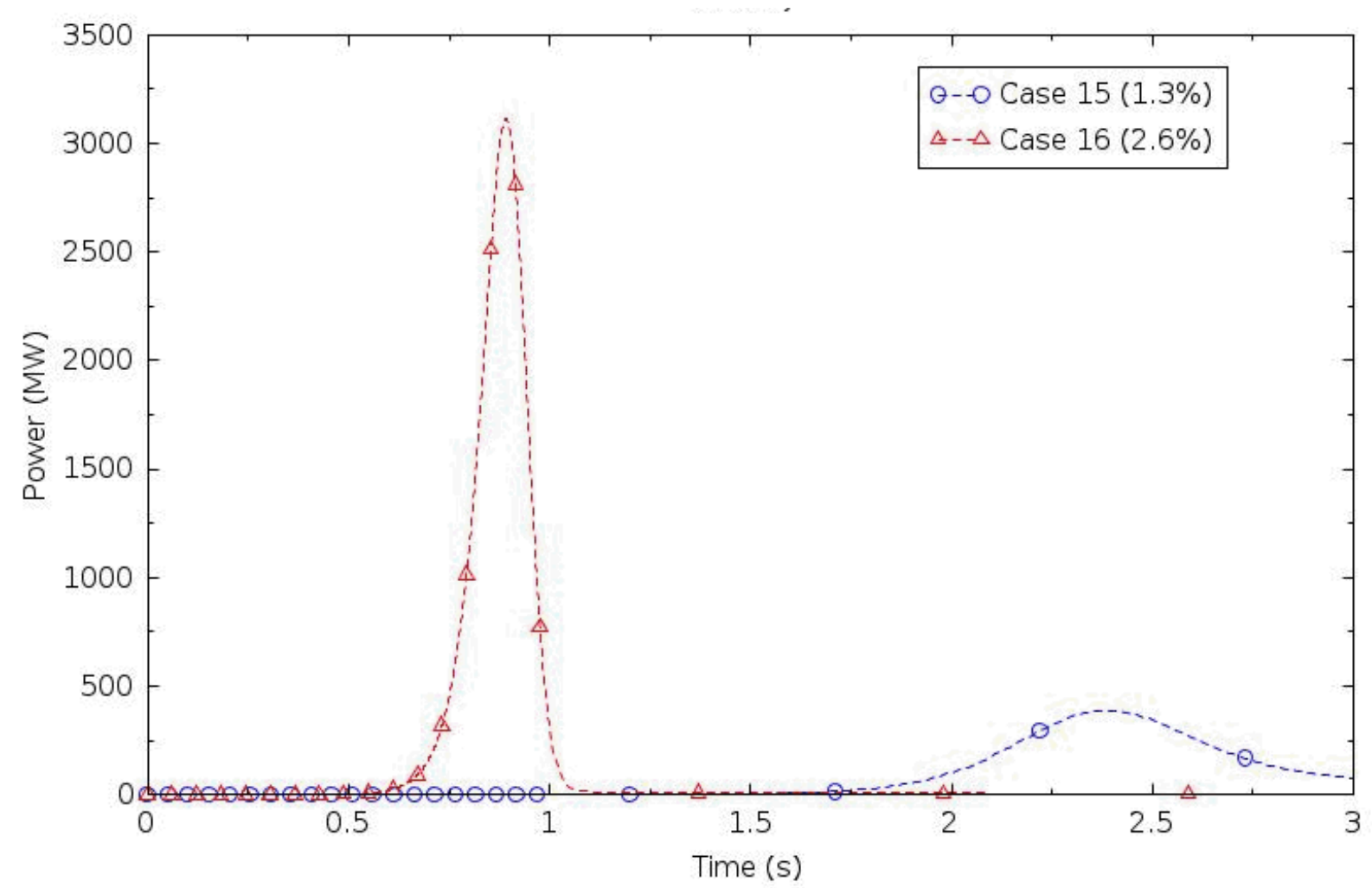

Fig. 12. The Effects of Clipping on Reactor Power at an Energy Deposition of 500 MJ.

The effects of the rate of reactivity insertion during clipping are illustrated in Fig. 13, which shows results from Cases 17 through 20 . All of these cases were initiated by a $4.5 \% \Delta \mathrm{k} / \mathrm{k}$ step insertion of reactivity and were clipped to achieve an energy deposition of about $625 \mathrm{MJ}$ at 60 s. Cases 17, 18, and 19 were clipped with the transient rods, but the rods were assumed to 
move at different speeds between $140 \mathrm{in} . / \mathrm{s}(3.556 \mathrm{~m} / \mathrm{s})$ and $250 \mathrm{in} . / \mathrm{s}(6.35 \mathrm{~m} / \mathrm{s})$. The transient rods can only move as quickly as $140 \mathrm{in.} / \mathrm{s}(3.556 \mathrm{~m} / \mathrm{s})$ with the current design, but faster rod movement would require facility modifications. Case 20 was clipped with a hypothetical ${ }^{3} \mathrm{He}$ system, which was assumed to insert a reactivity of $-5 \% \Delta \mathrm{k} / \mathrm{k}$ over a $0.005 \mathrm{~s}$ interval. Increasing the rod speed from $140 \mathrm{in} . / \mathrm{s}(3.556 \mathrm{~m} / \mathrm{s})$ to $200 \mathrm{in} . / \mathrm{s}(5.08 \mathrm{~m} / \mathrm{s})$ reduced the pulse width by $0.0117 \mathrm{~s}$. Increasing the rod speed from $200 \mathrm{in} . / \mathrm{s}(5.08 \mathrm{~m} / \mathrm{s})$ to $250 \mathrm{in} . / \mathrm{s}(6.35 \mathrm{~m} / \mathrm{s})$ reduced the pulse width by another $0.0066 \mathrm{~s}$. The pulse width was reduced by another $0.0313 \mathrm{~s}$ with the hypothetical ${ }^{3} \mathrm{He}$ system. In summary, increasing the speed of the transient rods reduces the pulse width, but the reduction is far more dramatic with the hypothetical ${ }^{3} \mathrm{He}$ system.

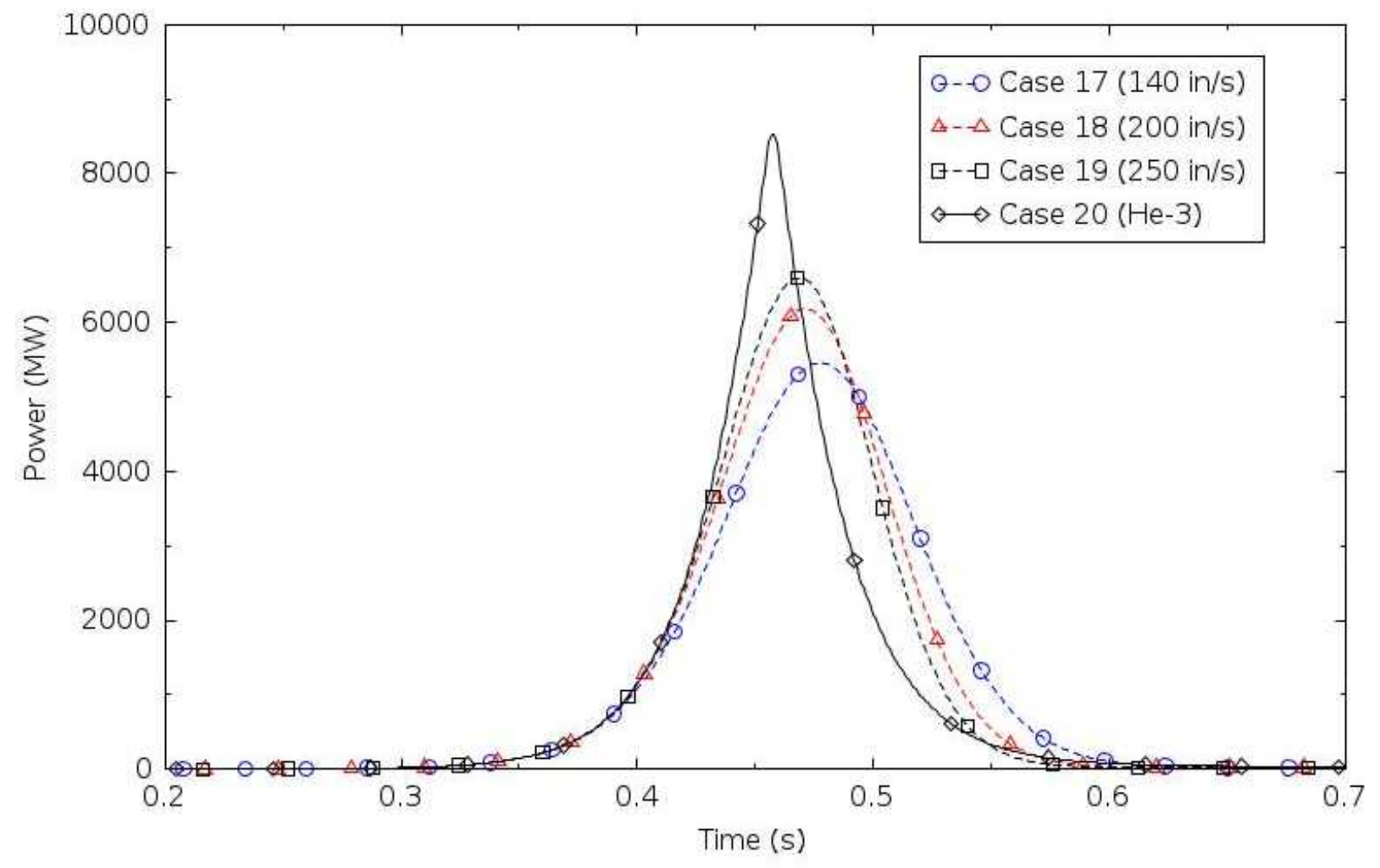

Fig. 13. The Effects of Clipping on Reactor Power at an Energy Deposition of 625 MJ. 
The effects of a larger initial reactivity insertion when the ${ }^{3} \mathrm{He}$ system is used for clipping are shown in Fig. 14, which compares results from Cases 20 and 21. Increasing the initial reactivity insertion from $4.5 \% \Delta \mathrm{k} / \mathrm{k}$ to $5.1 \% \Delta \mathrm{k} / \mathrm{k}$ caused the pulse width to increase by $0.0038 \mathrm{~s}$. A larger step insertion causes the pulse width to decrease during natural transients, but not necessarily during clipped transients as shown here. Figure 15 shows the effect of energy deposition on pulse width during transients clipped with the hypothetical ${ }^{3} \mathrm{He}$ system for initial reactivity insertions of $4.5 \% \Delta \mathrm{k} / \mathrm{k}$ and $5.1 \% \Delta \mathrm{k} / \mathrm{k}$. The higher initial reactivity insertion results in a lower minimum pulse width, but the reactivity insertion affects the energy deposition at which the minimum occurs. The minimum pulse width occurs at about $700 \mathrm{MJ}$ for an initial step insertion of $4.5 \% \Delta \mathrm{k} / \mathrm{k}$, but at about $1000 \mathrm{MJ}$ for an initial insertion of $5.1 \% \Delta \mathrm{k} / \mathrm{k}$. Since the pulse width depends on the energy deposition, increasing the initial step insertion can be counterproductive for obtaining a smaller pulse width. 


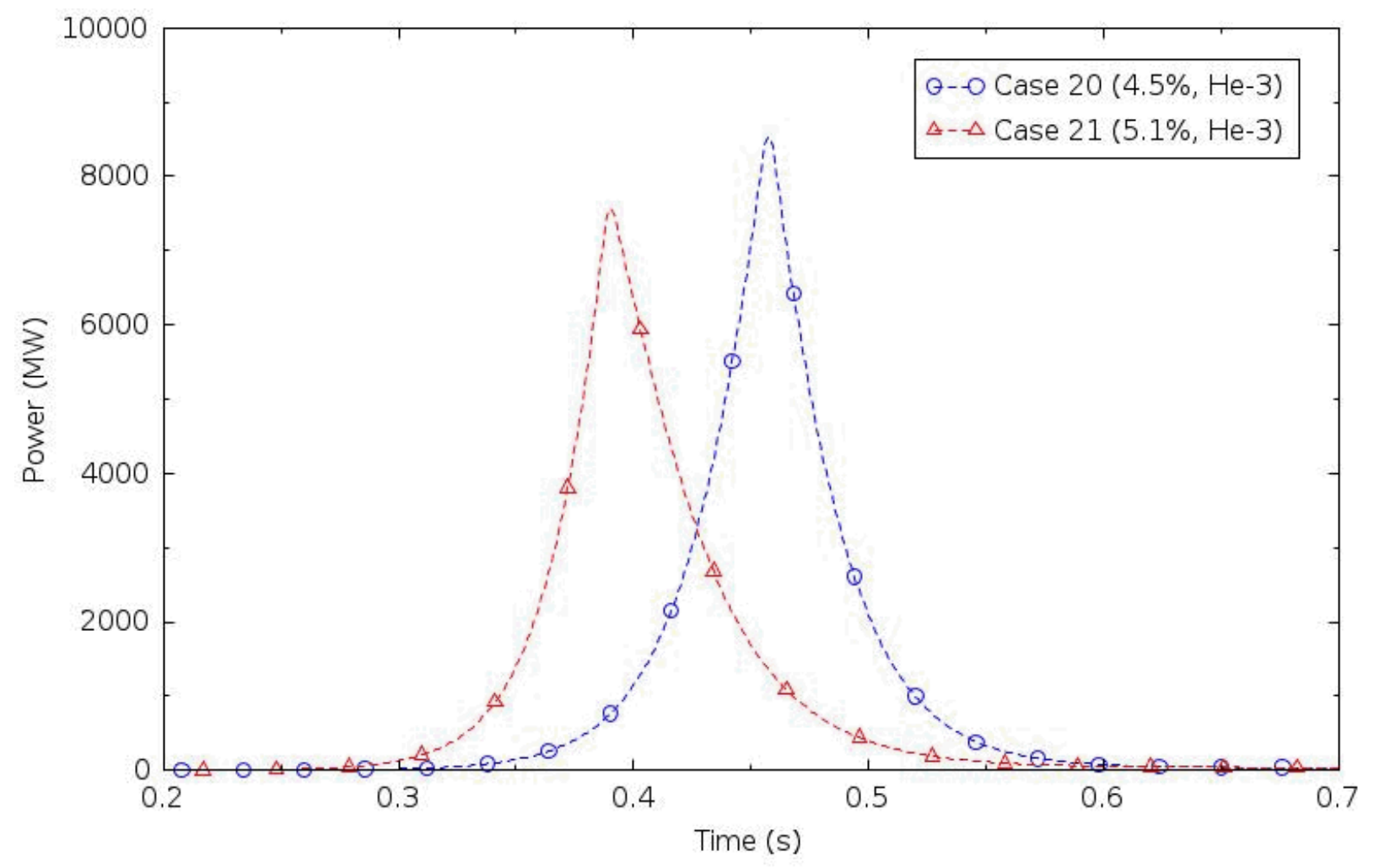

Fig. 14. The Effects of Initial Reactivity Insertion on Core Power using the ${ }^{3} \mathrm{He}$ System for Clipping. 


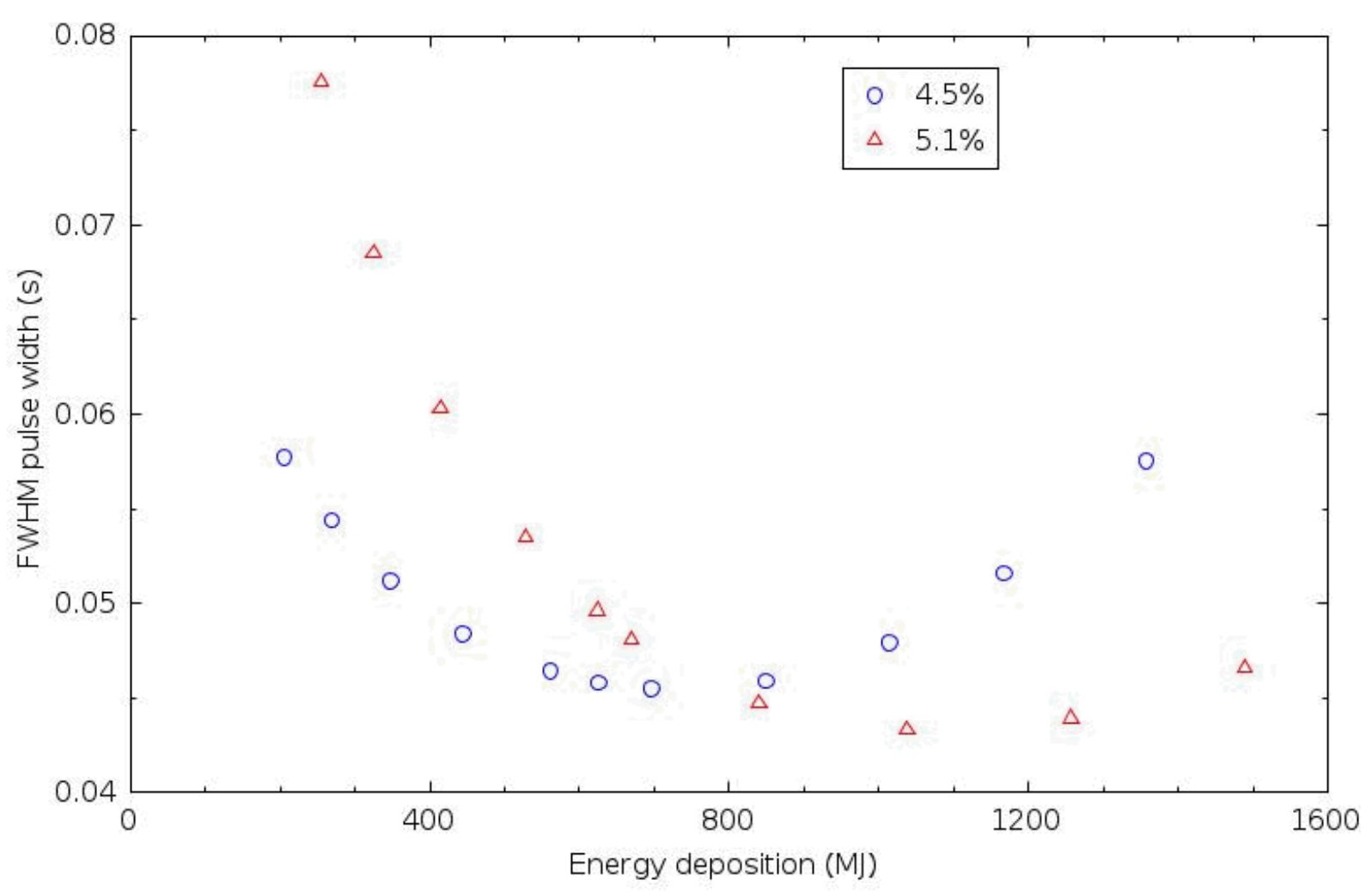

Fig. 15. Pulse Width versus Energy Deposition for Different Initial Reactivity Insertions.

\subsection{Core Power Flattening Studies}

Although not as effective as enhanced clipping, the kinetic studies summarized in Section 2.1 suggested a moderate benefit to minimizing pulse widths in cases where greater step insertions were permitted. A short summary regarding the core power flattening studies was previously presented at the American Nuclear Society (ANS) Annual Meeting in Philadelphia, Pennsylvania 17-21 June 2018 (Bess, et al., 2018), but is discussed in more detail herein. As shown in Table 2, increased steps insertions paired with enhanced clipping were found to provide different pulse width minimums at increased transient energies. These findings suggested that increased steps insertions, while not singularly effective in achieving PWR HZPRIA pulse widths, could be instrumental in optimizing experiment parameters to achieve both 
desired pulse widths and specimen energy injections. Additionally, any efforts enabling increased step insertions, since enhanced clipping would not be credited as a safety system to control core energy release, must enable TREAT to tolerate higher energy depositions; giving the facility greater capability for higher powers and/or longer run times in other types of transients.

While increased step insertions would offer various benefits, some facility systems, operational strategy, and/or safety basis modifications could be needed. For example, the reactor trip system minimum period set point of $23 \mathrm{~ms}$ would need to be reduced so that, if such a transient were initiated, it would not be immediately terminated. While not a major physical modification to the facility, this adjustment would likely require safety basis revisions to demonstrate that the possibility of increased fuel temperature would be acceptable. To facilitate such a scenario, nuclear investigations were performed to determine whether core management methods, assisted by modern three-dimensional computational capabilities, could be employed to flatten the core power profile (i.e. reduce to the local to average peaking ratio in limiting fuel assemblies). Such a strategy could enable more total core energy with little-to-no change in peak fuel assembly temperature. Core power flattening studies were performed for five primary core configurations of TREAT (also see Fig. 16):

- The current half-slot core with 48-in. ( 1.22 m) hodoscope assembly elements

- A full-slot core with 48-in. ( 1.22 m) hodoscope assembly elements

- A half-slot core with 24-in. $(\sim 61 \mathrm{~cm})$ length fueled hodoscope assembly elements

- A full-slot core with 24-in. $(\sim 61 \mathrm{~cm})$ length fueled hodoscope assembly elements

- A core loading with no hodoscope slot

Slotted assemblies are designed with the fuel section of the assembly replaced by an empty zircaloy frame to create an air channel through the assembly, as shown in Fig. 16 and Fig. 
17. A half-slotted core has nine slotted assemblies placed between the experiment at the center and the edge of the core (typically the north) creating an air channel from core center to one side of the reactor. A full-slotted core adds an additional nine slotted assemblies on the opposite side of the experiment (typically to the south) creating an air channel from one side of the core completely to the other side, only interrupted by the experiment located in the center of the slot. Slotted core configurations typically serve to provide a direct path from the experiment to the fast neutron hodoscope placed to the north side of TREAT. The half-slotted arrangement requires less fuel removal from the core and results in greater available core excess reactivity than the full slotted arrangement, thus allowing for experiments and vehicles with greater negative worths to be tested, or higher power transient tests to be performed. Full-slotted core loadings allow for cleaner hodoscope measurements with reduced background neutron detections from the reactor, as fueled TREAT assemblies are not placed in the direct path of the hodoscope. To facilitate neutron noise reduction in the half-slotted core arrangement, unfueled graphite assemblies can be placed directly to the south of the experiment test vehicle.

The positions of the control rods are shown in Fig. 17. The compensation rods typically are withdrawn during experimentation and inserted into the core to keep the reactor subcritical during experiment loading and unloading. For natural burst operation the reactor is brought critical with all compensation and transient rods fully withdrawn and criticality maintained with the control/shutdown rods partially inserted. Prior to a transient, the transient rods are inserted to a "cocked" position of prescribed worth and the control/shutdown rods partially removed to compensate, maintaining core criticality. The transient rods are then ejected to perform the transient test. All control rods are fully inserted at the end of a transient test. It should be noted that significant core upgrade was performed between 1988 and 1990; while most characteristics 
of the core itself remained unchanged, the arrangement and operation of the control rods is clearly different between core loadings prior to and after this upgrade (Robinson and Bauer 1988, Robinson and Bauer 1994). 


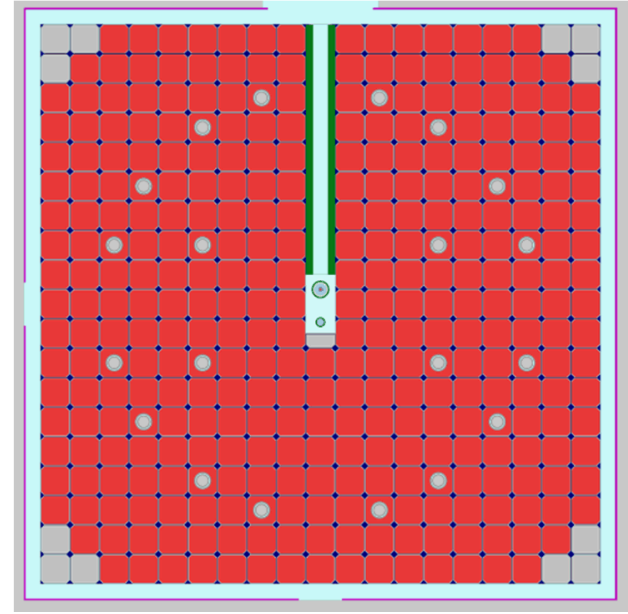

Half-Slotted Core

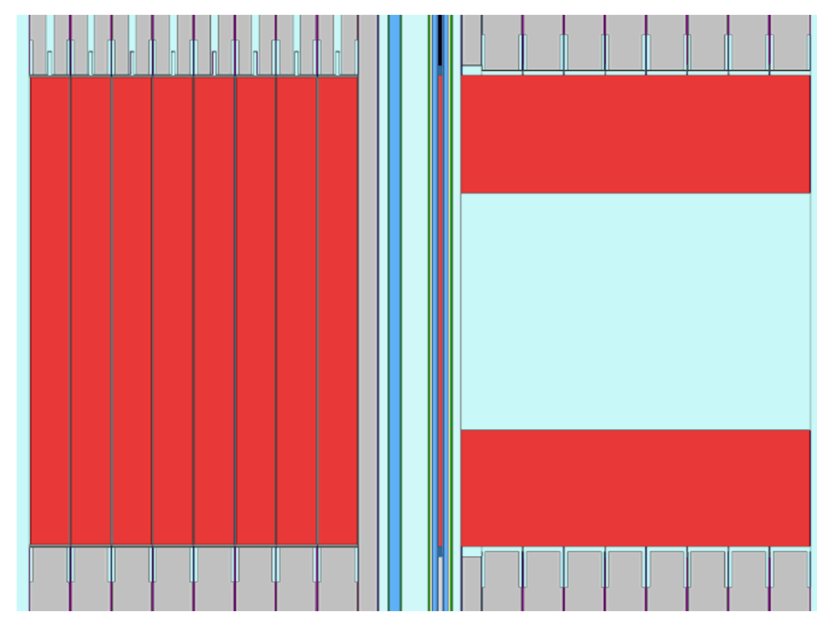

24-inch $(\sim 61 \mathrm{~cm})$ High Half-Slotted Core

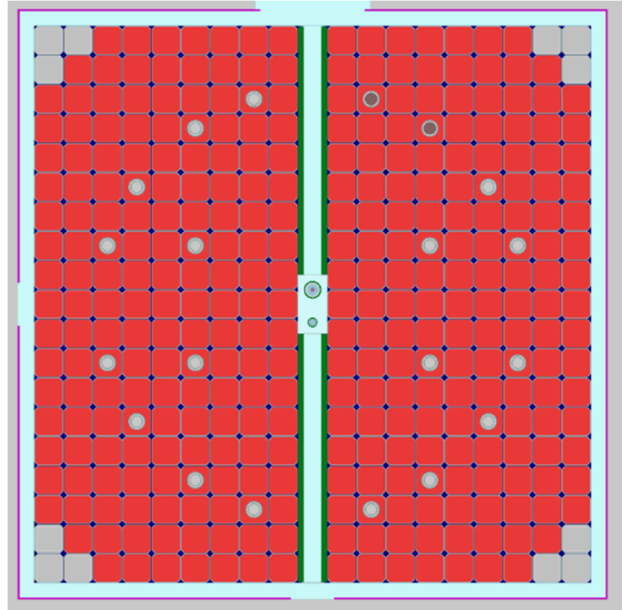

Full-Slotted Core

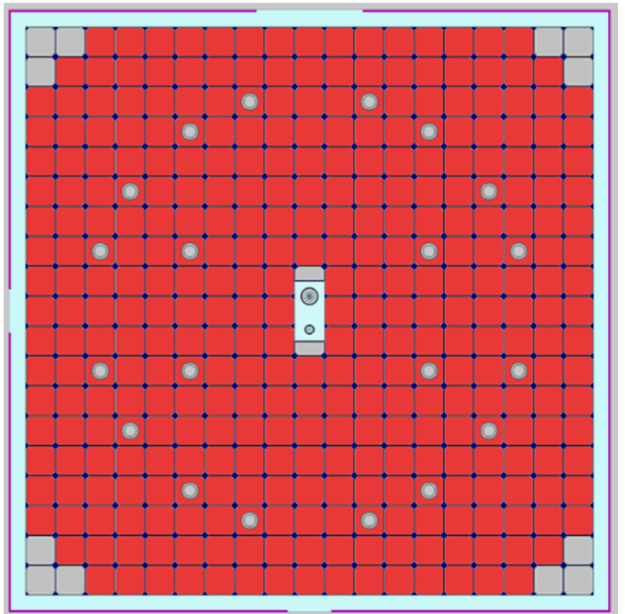

Core with No Hodoscope Slot

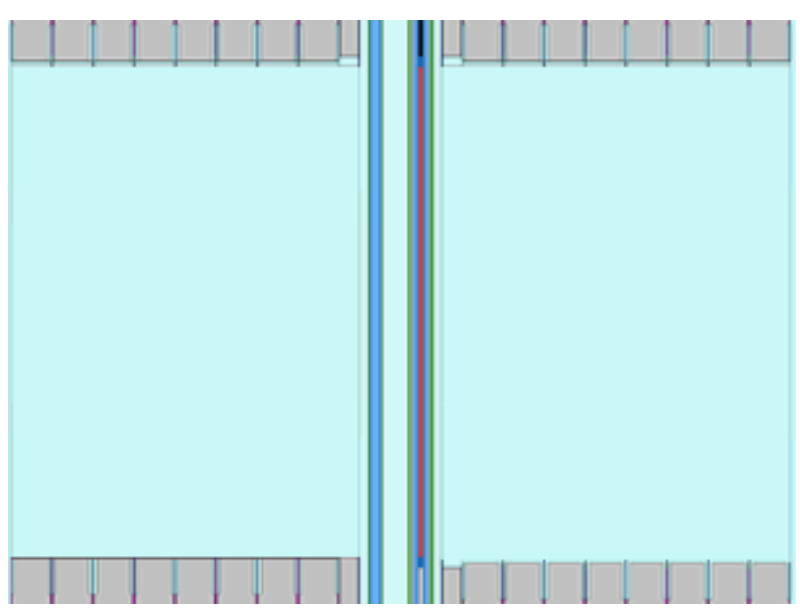

48-inch ( 1.22 m) High Full-Slotted Core

Fig. 16. Core Arrangements for TREAT Core Power Flattening Studies 


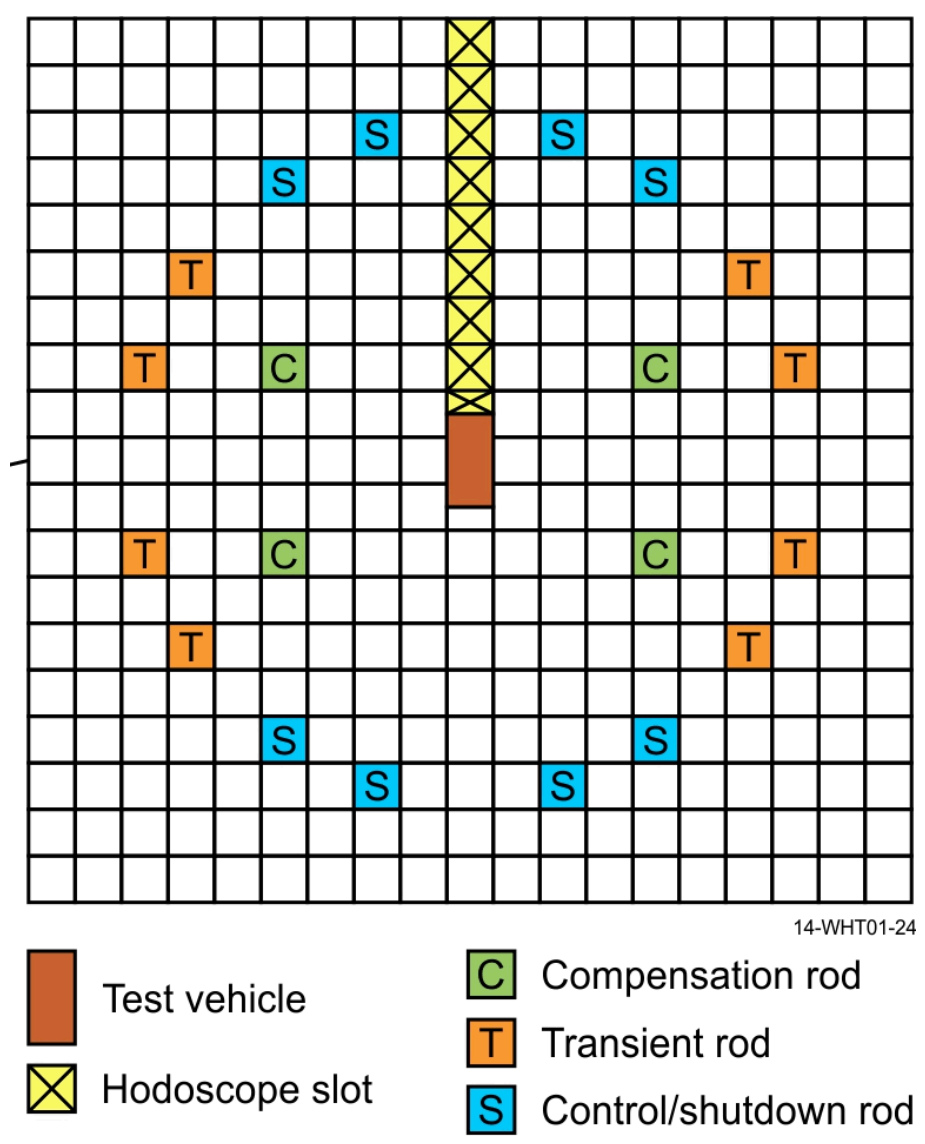

Fig. 17. Current Control Rod Arrangement in TREAT.

Simulations of the various TREAT loadings were performed with Serpent 3D MonteCarlo code (Leppanen, et al., 2015) version 2.1.27 analysis using ENDF/B-VII.1 neutron cross section library data (Chadwick, et al., 2011). Axial power distributions were tabulated for each fueled assembly for 12 vertical regions within the active core region of the fueled core to approximate expected assembly and local power peaking performance. Core variations were developed in an effort to minimize power peaking throughout the TREAT reactor recognizing performance constraints of existing assembly types and arrangements would dictate the true minimal values that could be obtained. Target $k_{\text {eff }}$ values of between 1.045 and 1.050 were 
desired to simulate reactivity insertion from a transient while maintaining sufficient negative reactivity within the transient control rods to ensure complete reactor shutdown.

One of the early core variation concepts included investigation into the modification of existing hodoscope assemblies include reflector material to prevent neutron leakage into the hodoscope slot and out of the core. Various materials were investigated with thicknesses of up to $4 \mathrm{~cm}$ along each side of the hodoscope slot. The addition of material along the hodoscope length provided the reflection necessary to help reduce core leakage and balance power distributions throughout the core while minimizing the width of the "visible" vertical slot leading from the experiment assembly to the hodoscope. The narrowed view window would have little negative impact for small bundle or single pin tests. Figure 18 shows an example of the addition of neutron reflector material, in this instance beryllium, to the 48-in. hodoscope assemblies for a half-slot core. The currently evaluated ideal modification would include approximately $2.5 \mathrm{~cm}$ nuclear grade graphite reflectors along each side of the slotted assemblies, whether 48-in. or 24in. 

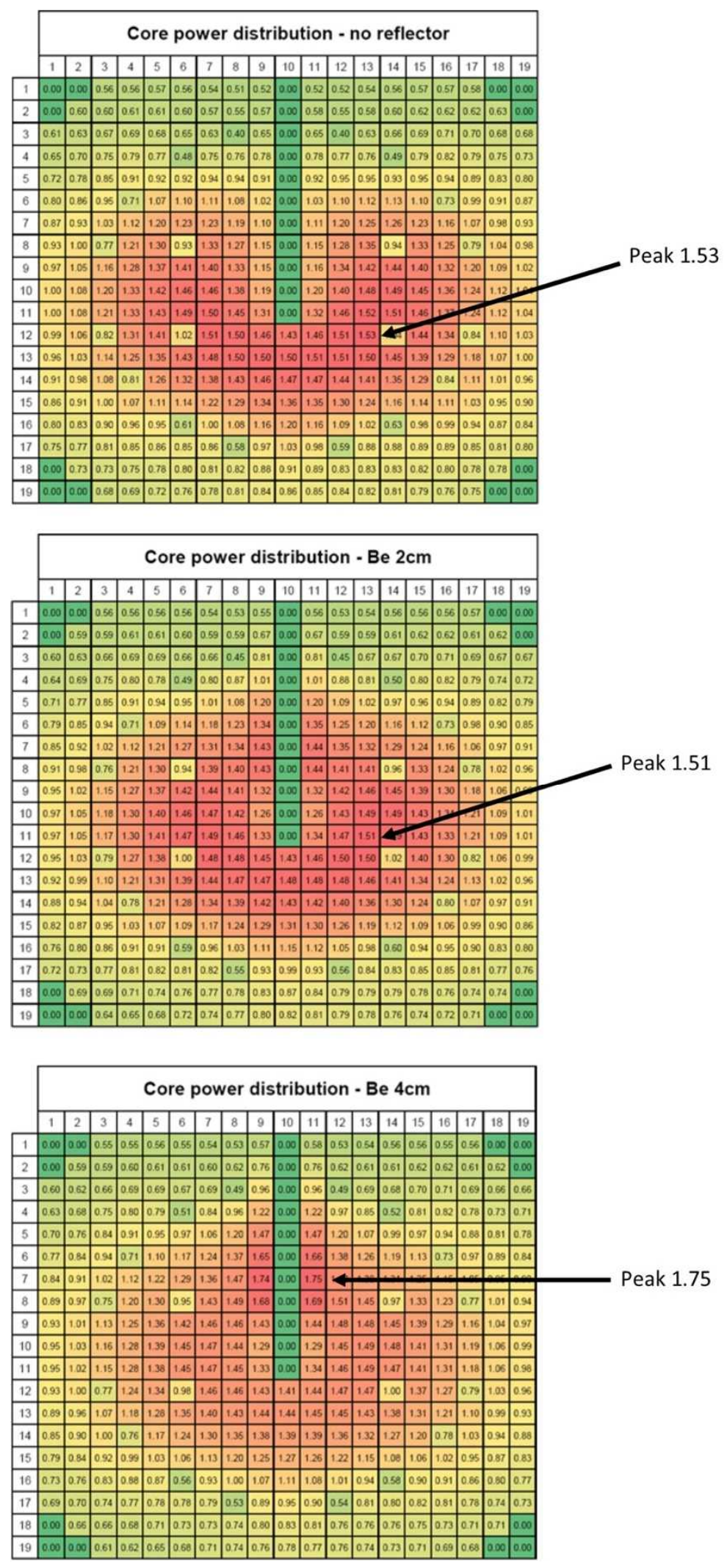

Fig. 18. Be-Reflected Hodoscope Slot Assembly Average to Core Average Ratios. 
In some cases, the addition of reflectors along the hodoscope path helps improve core power distribution but does not significantly address the need to flatten the core power distribution. As a result, this concept was deprioritized from further consideration. The optimum core design will depend on many variables, including, but not limited to, the following:

- Design and location of the experiment, including test vehicle and instrumentation (i.e. experiment "worth")

- Desired primary core loading type (i.e. hodoscope required, and if so, what type of slot)

- Desired experiment measurement (i.e. hodoscope requirement with width and height of slot window)

- Desired energy deposition

- Desired transient prescription

Further future development of the core to include additional assembly types, such as low enriched uranium (LEU) fuel, also indicated a need to prepare a process for core analysis to address core power flattening instead of a single analysis solution. The opportunity to utilize and implement new tools and procedures to efficiently and rapidly explore core design opportunities was essential to addressing the current challenge with a near-comprehensive strategy. Still, the procedure required manual input to drive the iteration process with different assembly types and arrangement strategies. It is recommended that further automation of the process be explored that can implement all existing assembly types with the opportunity to include future assemblies such that future experiment designs can similarly be optimized for core power performance.

Strategic placement of TREAT assemblies with reduced fuel content were the most effective in promoting the flattening of the core power. Spare control rod fueled assemblies (without additional control rods), 24-in. fueled hodoscope assemblies, and 48-in. hodoscope 
assemblies effectively reduced power peaking at an increasing loss of core excess reactivity. Graphite dummy assemblies, while eliminating the power peaking in a given core location, would sometimes dramatically increase power peaking in the adjacent fuel assemblies due to increased neutron moderation and reflection. Graphite dummy assemblies were not always implemented as a practical approach to core flattening in some optimized core designs; however, they were successfully utilized in others. Optimization strategies are very core-loading dependent. Control rod fueled assemblies are limited to unique core positions within the reactor, except for a single vertical access fueled assembly that is a control rod fueled assembly with a standard assembly bottom fitting and can be placed anywhere within the core.

Aside from the addition of graphite reflector paneling within the hodoscope slotted assemblies, the rebalancing of core power could be instigated with repositioning of the control rods. Specifically, criticality maintained with compensation rods instead of the control/shutdown rods can significantly shift power peaking from the central portions of the core. During a transient, the transient control rods are completely withdrawn. Due to core symmetry, it is desirable to similarly have the control/shutdown rods completely withdrawn prior to transient initiation. In half-slot cores, having the north pair of compensation rods slightly withdrawn in comparison to the south pair of compensation rods can also facilitate balancing of core power distribution. Operational specifications for TREAT need modified and approved to allow for practical implementation of this power flattening strategy. Further investigation into individual compensation rod management to account for slight east-to-west core imbalances due to the presence of the thermal column will be needed.

Some example core loadings optimized to minimize peak power while maintaining the desired core reactivity are shown in Fig. 19 for the 48-inch half-slot core. The peak power 
positions were replaced by 24 -in. hodoscope assemblies. The control/shutdown rods are withdrawn, and reactivity is controlled by the compensation rods at different north/south banked pair positions. The scatterplot provides the many sample cases investigated, with a clear limit to how much power peaking must be accepted to accompany a given reactivity loading within the core.

Example loadings for the 48-in. full-slot core are shown in Fig. 20. The challenge with the full-slot core is obtaining the desired reactivity because so many fueled elements are removed through the center of the core. The addition of 24 -in. hodoscope assemblies to reduce power peaking further reduces total available core reactivity.

Figure 21 provides the example loadings for the 24 -in. half-slot core using either graphite dummy assemblies or additional strategically placed 24 -in. hodoscope assemblies placed in the peak power positions. Figure 22 provides example loadings for the 24 -in. full-slot core with graphite dummy assemblies utilized to reduce some of the peak power positions and redistribute into adjacent fuel assemblies.

Figure 23 shows example loadings for the core with no hodoscope slot. Graphite dummy assemblies served to mitigate and redistribute peak power positions. While optimization strategies were implemented for target reactivity, the distribution chart demonstrates that core excess reactivities are theoretically possible for up to almost $10 \% \Delta \mathrm{k} / \mathrm{k}$, which exceeds the current safety basis limit of $8 \% \Delta \mathrm{k} / \mathrm{k}$. Expanding the current reactor/experiment capabilities is possible when sacrificing the availability of the hodoscope slot and implementing different instrumentation and visualization strategies.

A boundary curve chart (see Fig. 24) was prepared to compare the limitations in power peaking reduction with the desired core excess reactivity. While a near-infinite possibility of core 
arrangements is possible, there are clear trends in the plots indicating what is likely possible with current core loadings for the proposed experiment design. Similar trending could be prepared for other experiment concepts as well as modifications to key reactor loading desires. Any point above and to the left of the lines in Fig. 24 is theoretically possible within the envelope of this analysis. More comprehensive analyses beyond those shown in Fig. 19 through Fig. 23 would need to be performed to attempt to shift any of the trend lines further down or to the right to effectively increase the coupled experiment/core design envelope.

In summary, this effort demonstrated that for a given core configuration, which depends highly on the reactivity worth of the experiment vehicle and the length of hodoscope slot. Modern three-dimensional Monte Carlo-based computational tools can be used to optimize the core power peaking profile. By replacing peak fuel assemblies with graphite dummy assemblies, fixing TREAT's various non-transient control rods at deliberate positions to hold down the "hot side" of the core, and balancing against the required excess reactivity needed in the transient rods, the limiting fuel assembly power can be reduced on the order of $\sim 20 \%$. This is an important discovery of TREAT's latent capabilities. These capabilities enable reduced pulse widths and allow for "uprating" the core's transient energy capacity by a significant amount. Investment in computational developments which automate the optimization process will be needed to streamline this strategy into an applicable design tool. 


\section{half slot core results}

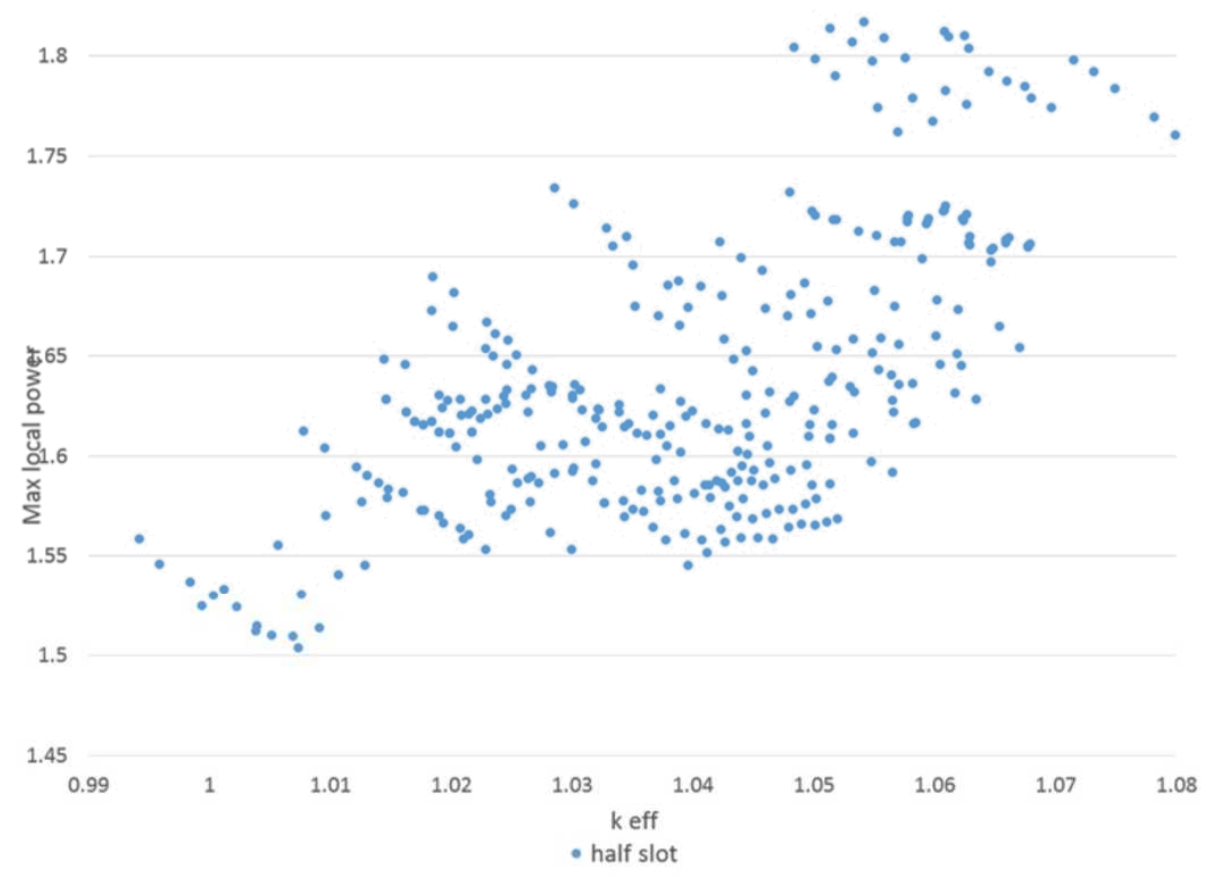

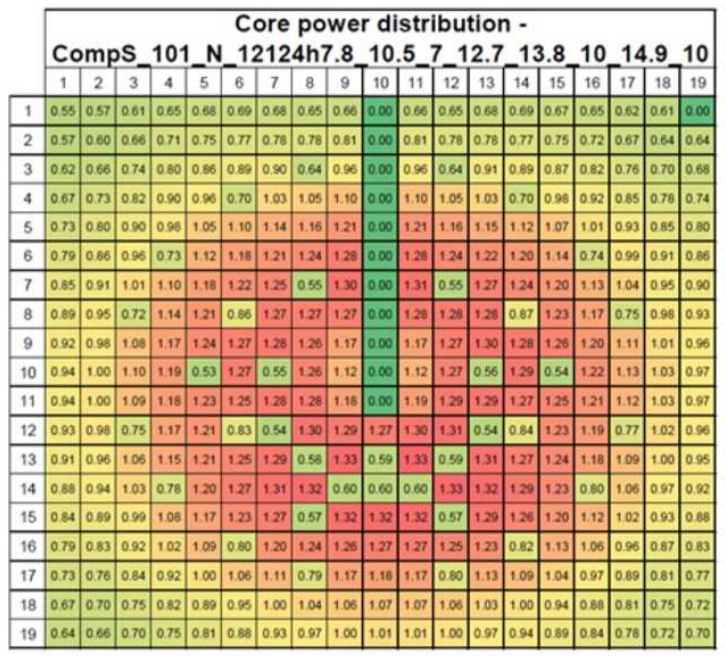

\begin{tabular}{|c|c|c|c|c|c|c|c|c|}
\hline \multicolumn{2}{|l|}{ POP } & \multicolumn{3}{|c|}{100000050050} & & \multirow{2}{*}{\multicolumn{2}{|c|}{$\begin{array}{l}\text { hodoscope } \\
\text { direction }\end{array}$}} & \\
\hline \multicolumn{2}{|c|}{ reflector width } & \multicolumn{3}{|c|}{$2.5 \mathrm{~cm}$} & & & & \\
\hline $\begin{array}{c}\text { MAX assembly } \\
\text { power }\end{array}$ & \multicolumn{2}{|c|}{1.33} & & KEFF & \multicolumn{4}{|c|}{$1.04546 \mathrm{E}+00+1 \cdot 3.9 \mathrm{E}-05$} \\
\hline $\begin{array}{l}\text { MAX local } \\
\text { power }\end{array}$ & \multicolumn{2}{|c|}{1.56} & \multicolumn{2}{|c|}{$\begin{array}{l}\text { heigth of the } \\
\text { MAX }\end{array}$} & \multicolumn{2}{|c|}{$5060 \mathrm{~cm}$} & & \\
\hline $\begin{array}{l}\text { Rod positions } \\
\text { (in Serpent) }\end{array}$ & c/s & 152.57 & $\begin{array}{l}\text { Comp } \\
\text { South }\end{array}$ & 101.69 & $\begin{array}{l}\text { Comp } \\
\text { North }\end{array}$ & 121.69 & Trans & 98.05 \\
\hline \multicolumn{2}{|c|}{ how much is inserted } & -22.01 & & 28.87 & & 8.87 & & -1.47 \\
\hline
\end{tabular}

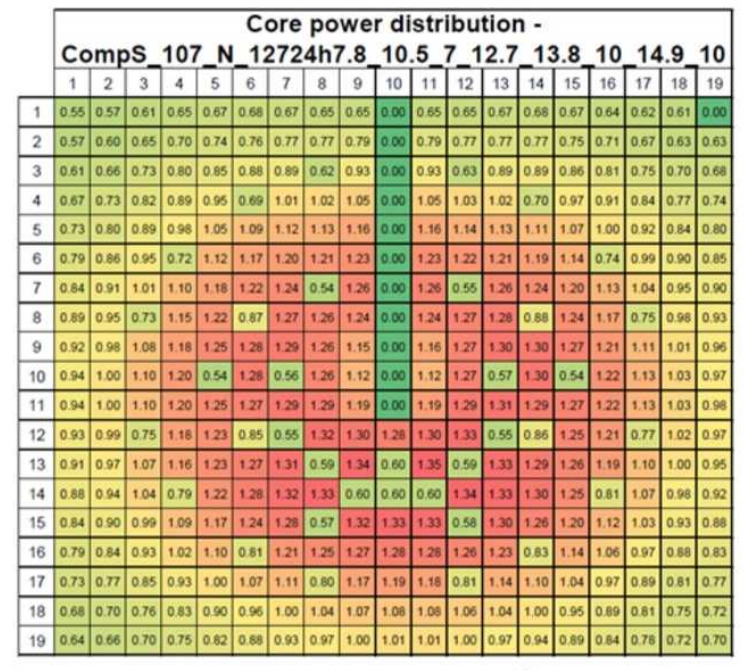

\begin{tabular}{|c|c|c|c|c|c|c|c|c|}
\hline \multicolumn{2}{|l|}{ POP } & \multicolumn{3}{|c|}{100000050050} & & \multirow{2}{*}{\multicolumn{2}{|c|}{$\begin{array}{l}\text { hodoscope } \\
\text { direction }\end{array}$}} & \\
\hline \multicolumn{2}{|c|}{ reflector width } & \multicolumn{3}{|c|}{$2 \mathrm{~cm}$} & & & & \\
\hline $\begin{array}{c}\text { MAX assembly } \\
\text { power }\end{array}$ & \multicolumn{2}{|c|}{1.35} & \multicolumn{2}{|r|}{ K EFF } & \multicolumn{4}{|c|}{$1.04724 \mathrm{E}+00+1-4.0 \mathrm{E}-05$} \\
\hline $\begin{array}{l}\text { MAX local } \\
\text { power }\end{array}$ & \multicolumn{2}{|c|}{1.57} & \multicolumn{3}{|c|}{$\begin{array}{l}\text { heigth of the } \\
\text { MAX }\end{array}$} & $5060 \mathrm{~cm}$ & & \\
\hline $\begin{array}{c}\text { Rod positions } \\
\text { (in Serpent) }\end{array}$ & $\mathbf{c} / \mathbf{S}$ & 152.57 & $\begin{array}{l}\text { Comp } \\
\text { South }\end{array}$ & 107.69 & $\begin{array}{l}\text { Comp } \\
\text { North }\end{array}$ & 127.69 & Trans & 98.05 \\
\hline \multicolumn{2}{|c|}{ how much is inserted } & -22.01 & & 22.87 & & 2.87 & & -1.47 \\
\hline
\end{tabular}

Fig. 19. 48-in. Half-Slot Core - Example Results. 


\section{full slot core results}

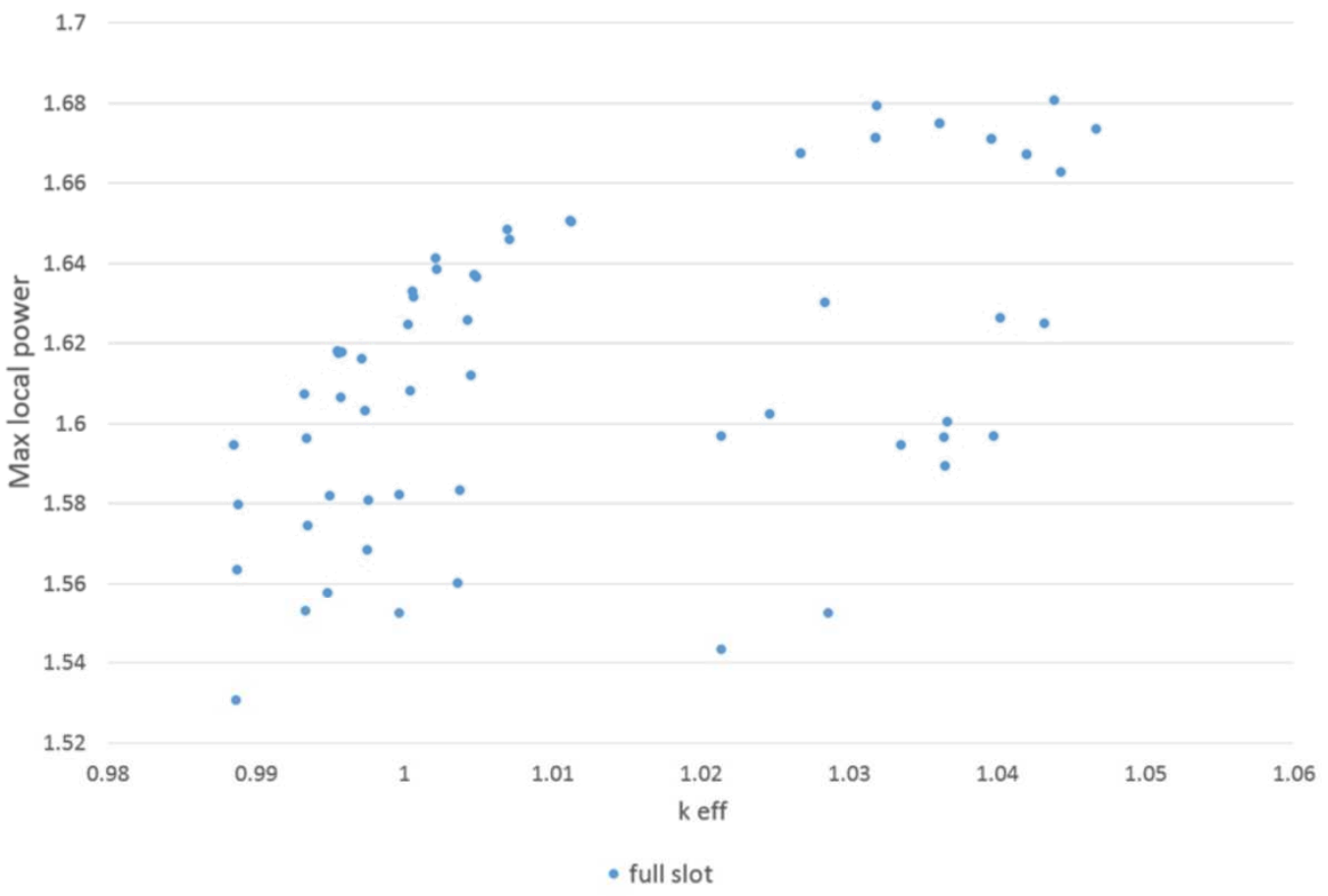

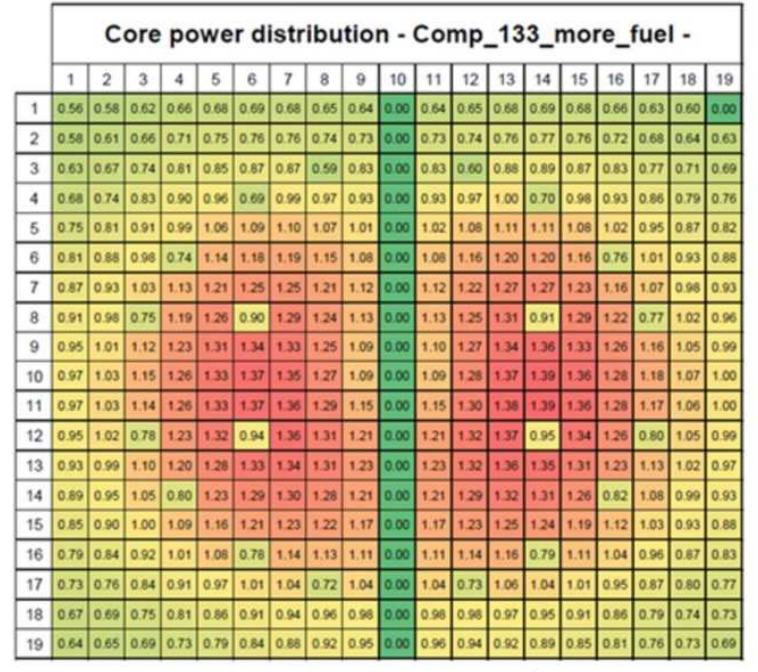

\begin{tabular}{|c|c|c|c|c|c|c|c|c|}
\hline \multicolumn{2}{|l|}{ POP } & \multicolumn{3}{|c|}{100000050050} & & \multirow{2}{*}{\multicolumn{2}{|c|}{$\begin{array}{l}\text { hodoscope } \\
\text { direction }\end{array}$}} & \\
\hline \multicolumn{2}{|c|}{ reflector width } & \multicolumn{3}{|c|}{$\cdot$} & & & & \\
\hline $\begin{array}{c}\text { MAX assembly } \\
\text { power }\end{array}$ & \multicolumn{2}{|c|}{1.39} & & KEFF & \multicolumn{4}{|c|}{$1.04672 \mathrm{E}+00+1-4.1 \mathrm{E}-05$} \\
\hline $\begin{array}{l}\text { MAX local } \\
\text { power }\end{array}$ & \multicolumn{2}{|c|}{1.67} & \multicolumn{2}{|c|}{$\begin{array}{l}\text { heigth of the } \\
\text { MAX }\end{array}$} & \multicolumn{2}{|c|}{$5060 \mathrm{~cm}$} & & \\
\hline $\begin{array}{c}\text { Rod positions } \\
\text { (in Serpent) }\end{array}$ & $\mathbf{c} / \mathbf{s}$ & 142.57 & $\begin{array}{l}\text { Comp } \\
\text { South }\end{array}$ & $\mid 133.69$ & $\begin{array}{l}\text { Comp } \\
\text { North }\end{array}$ & 133.69 & Trans & $\mathbf{9 8 . 0 5}$ \\
\hline \multicolumn{2}{|c|}{ how much is inserted } & -12.01 & & -3.13 & & -3.13 & & -1.47 \\
\hline
\end{tabular}

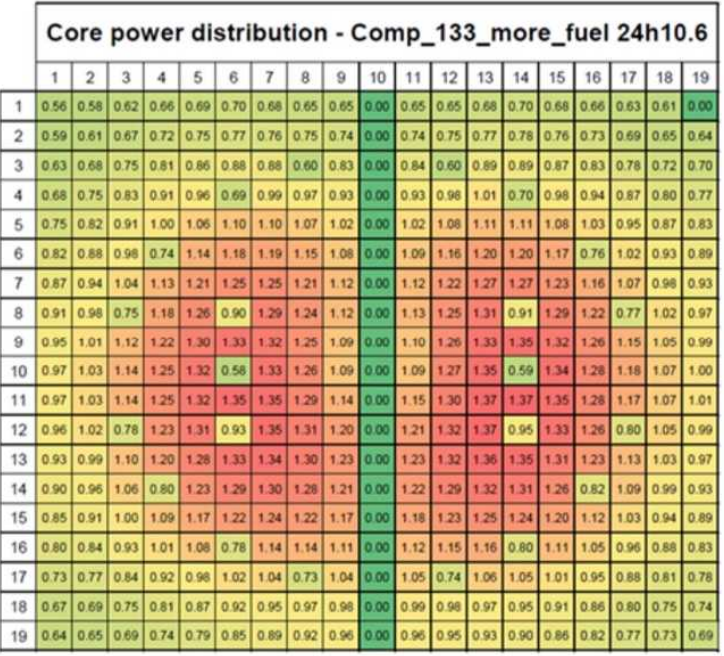

\begin{tabular}{|c|c|c|c|c|c|c|c|c|}
\hline \multicolumn{2}{|l|}{ POP } & \multicolumn{3}{|c|}{100000050050} & & \multirow{2}{*}{\multicolumn{2}{|c|}{$\begin{array}{l}\text { hodoscope } \\
\text { direction }\end{array}$}} & \\
\hline \multicolumn{2}{|c|}{ reflector width } & \multicolumn{3}{|c|}{$\cdot$} & & & & \\
\hline $\begin{array}{c}\text { MAX assembly } \\
\text { power }\end{array}$ & \multicolumn{2}{|c|}{1.37} & \multicolumn{2}{|r|}{ K EFF } & \multicolumn{4}{|c|}{$1.04328 \mathrm{E}+00+1-4.1 \mathrm{E}-05$} \\
\hline $\begin{array}{l}\text { MAX local } \\
\text { power }\end{array}$ & \multicolumn{2}{|c|}{1.62} & & $\begin{array}{l}\text { heigth of the } \\
\text { MAX }\end{array}$ & \multicolumn{2}{|c|}{$5060 \mathrm{~cm}$} & & \\
\hline $\begin{array}{c}\text { Rod positions } \\
\text { (in Serpent) }\end{array}$ & $\mathrm{c} / \mathrm{s}$ & 142.57 & $\begin{array}{l}\text { Comp } \\
\text { South }\end{array}$ & 133.69 & $\begin{array}{l}\text { Comp } \\
\text { North }\end{array}$ & 133.69 & Trans & 98.05 \\
\hline \multicolumn{2}{|c|}{ how much is inserted } & -12.01 & & -3.13 & & -3.13 & & -1.47 \\
\hline
\end{tabular}

Fig. 20. 48-in. Full-Slot Core - Example Results. 


\section{4 half slot core results}

1.75

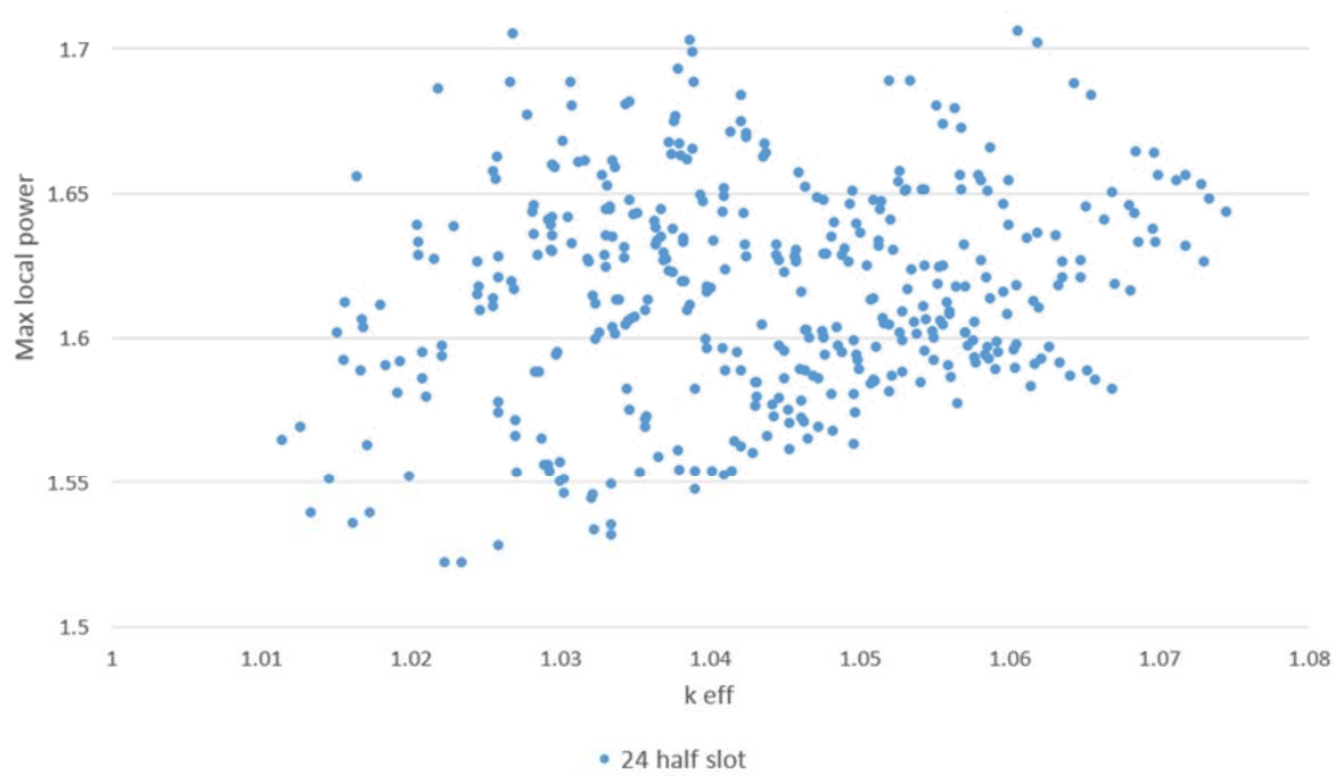

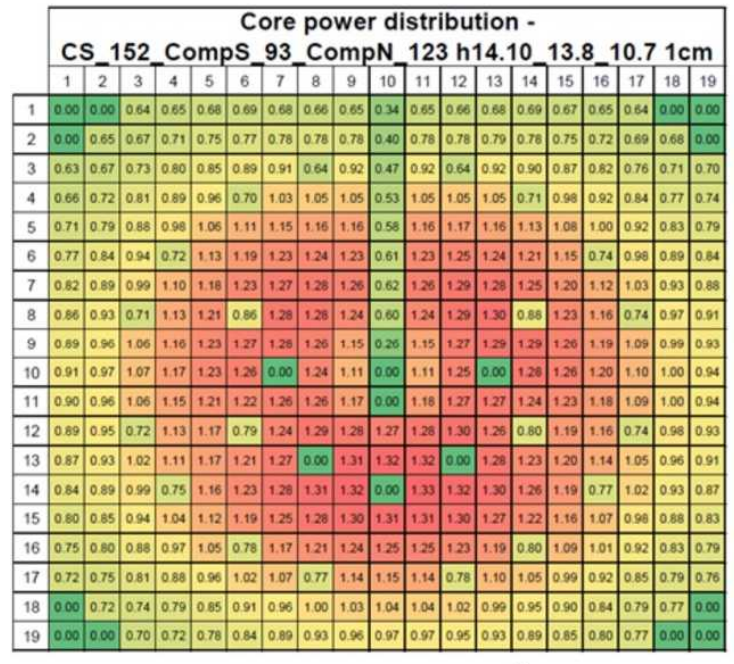

\begin{tabular}{|c|c|}
\hline POP & 1000 \\
\hline reflector width & \\
\begin{tabular}{|c|c|}
\hline \multicolumn{2}{|c|}{ MAX assembly } \\
power
\end{tabular} & 1.33 \\
\hline $\begin{array}{c}\text { MAX local } \\
\text { power }\end{array}$ & 1.56 \\
\hline
\end{tabular}

\begin{tabular}{|c|c|c|c|c|c|c|c|c|}
\hline $\begin{array}{l}\text { Rod positions } \\
\text { (in Serpent) }\end{array}$ & $\mathrm{C} / \mathrm{s}$ & 2.57 & $\begin{array}{l}\text { Comp } \\
\text { South }\end{array}$ & 93.69 & $\begin{array}{l}\text { Comp } \\
\text { North }\end{array}$ & 123.69 & Trans & 98.05 \\
\hline how much is in & ted & -22.01 & & 36.87 & & 6.87 & & -1.47 \\
\hline
\end{tabular}

\section{Core power distribution - CompS_73_N_113}

$$
24 \mathrm{~h} 7.8 \quad 10.7 \quad 13.8 \quad 14.10 \quad 15.92 \mathrm{~cm}
$$

\begin{tabular}{c|c|c|c|c|c|c|c|c|c|c|c|c|c|c|c|c|c|c|c|} 
& 1 & 2 & 3 & 4 & 5 & 6 & 7 & 8 & 9 & 10 & 11 & 12 & 13 & 14 & 15 & 16 & 17 & 18 & 19 \\
\hline 1 & 0.00 & 0.60 & 0.63 & 0.67 & 0.70 & 0.71 & 0.71 & 0.68 & 0.57 & 0.35 & 0.67 & 0.66 & 0.71 & 0.71 & 0.70 & 0.67 & 0.64 & 0.63 & 0.00 \\
\hline
\end{tabular} \begin{tabular}{|llllllllllll|l|lllllllll}
2 & 0.60 & 0.62 & 0.67 & 0.73 & 0.7 & 0.80 & 0.81 & 0.81 & 0.82 & 0.42 & 0.82 & 0.81 & 0.81 & 0.81 & 0.78 & 0.74 & 0.69 & 0.65 & 0.65 \\
\hline
\end{tabular}

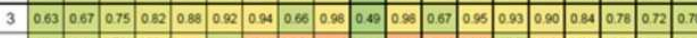

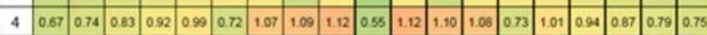
\begin{tabular}{|l|l|l|l|l|l|l|l|l|l|l|l|l|l|l|l|l|l|l|l|l|}
\hline 5 & 0.73 & 0.81 & 0.91 & 1.00 & 1.08 & 1.13 & 1.18 & 1.20 & 1.23 & 0.61 & 1.23 & 1.21 & 1.19 & 1.15 & 1.10 & 1.03 & 0.94 & 0.86 & 0.81 \\
\hline
\end{tabular}

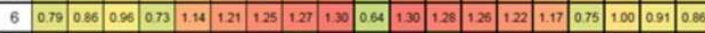

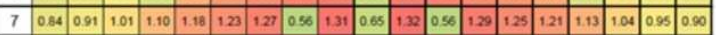
\begin{tabular}{|l|l|l|l|l|l|l|l|l|l|l|l|l|l|l|l|l|l|l|l|}
\hline 8 & 0.88 & 0.94 & 0.72 & 1.14 & 1.20 & 0.85 & 1.26 & 1.20 & 1.28 & 0.61 & 1.26 & 1.30 & 1.20 & 0.86 & 1.23 & 1.17 & 0.74 & 0.96 & 0.93 \\
\hline
\end{tabular}

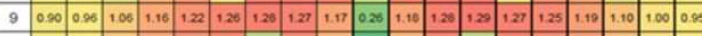

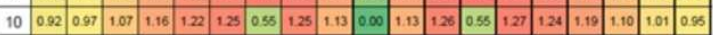

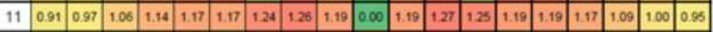

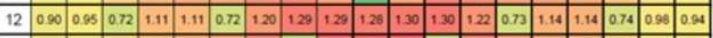

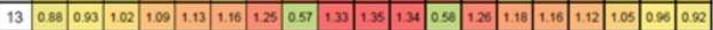

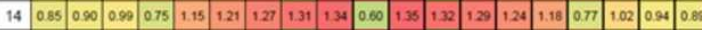

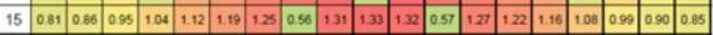

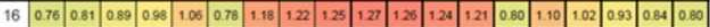

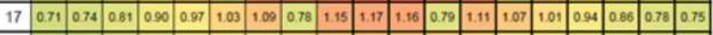

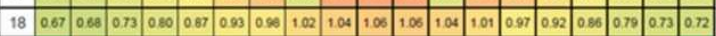

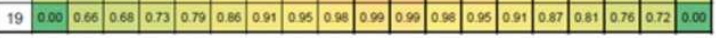

\begin{tabular}{|c|c|c|c|c|c|c|c|c|}
\hline \multicolumn{2}{|l|}{ POP } & \multicolumn{3}{|c|}{100000050050} & & \multirow{2}{*}{\multicolumn{2}{|c|}{$\begin{array}{l}\text { hodoscope } \\
\text { direction }\end{array}$}} & \\
\hline \multicolumn{2}{|c|}{ reflector width } & \multicolumn{3}{|c|}{$2 \mathrm{~cm}$} & & & & \\
\hline $\begin{array}{c}\text { MAX assembly } \\
\text { power }\end{array}$ & \multicolumn{2}{|c|}{1.35} & & KEFF & \multicolumn{4}{|c|}{$1.04531 \mathrm{E}+00+1 \cdot 3.9 \mathrm{E}-05$} \\
\hline $\begin{array}{l}\text { MAX local } \\
\text { power }\end{array}$ & \multicolumn{2}{|c|}{1.56} & \multicolumn{2}{|c|}{$\begin{array}{l}\text { heigth of the } \\
\text { MAX }\end{array}$} & \multicolumn{2}{|c|}{$5060 \mathrm{~cm}$} & & \\
\hline $\begin{array}{c}\text { Rod positions } \\
\text { (in Serpent) }\end{array}$ & $\mathbf{c} / \mathbf{S}$ & 152.57 & $\begin{array}{l}\text { Comp } \\
\text { South }\end{array}$ & 73.69 & $\begin{array}{l}\text { Comp } \\
\text { North }\end{array}$ & 113.69 & Trans & 98.05 \\
\hline \multicolumn{2}{|c|}{ how much is inserted } & -22.01 & & 56.87 & & 16.87 & & -1.47 \\
\hline
\end{tabular}

Fig. 21. 24-in. Half-Slot Core - Example Results. 


\section{4 full slot core results}

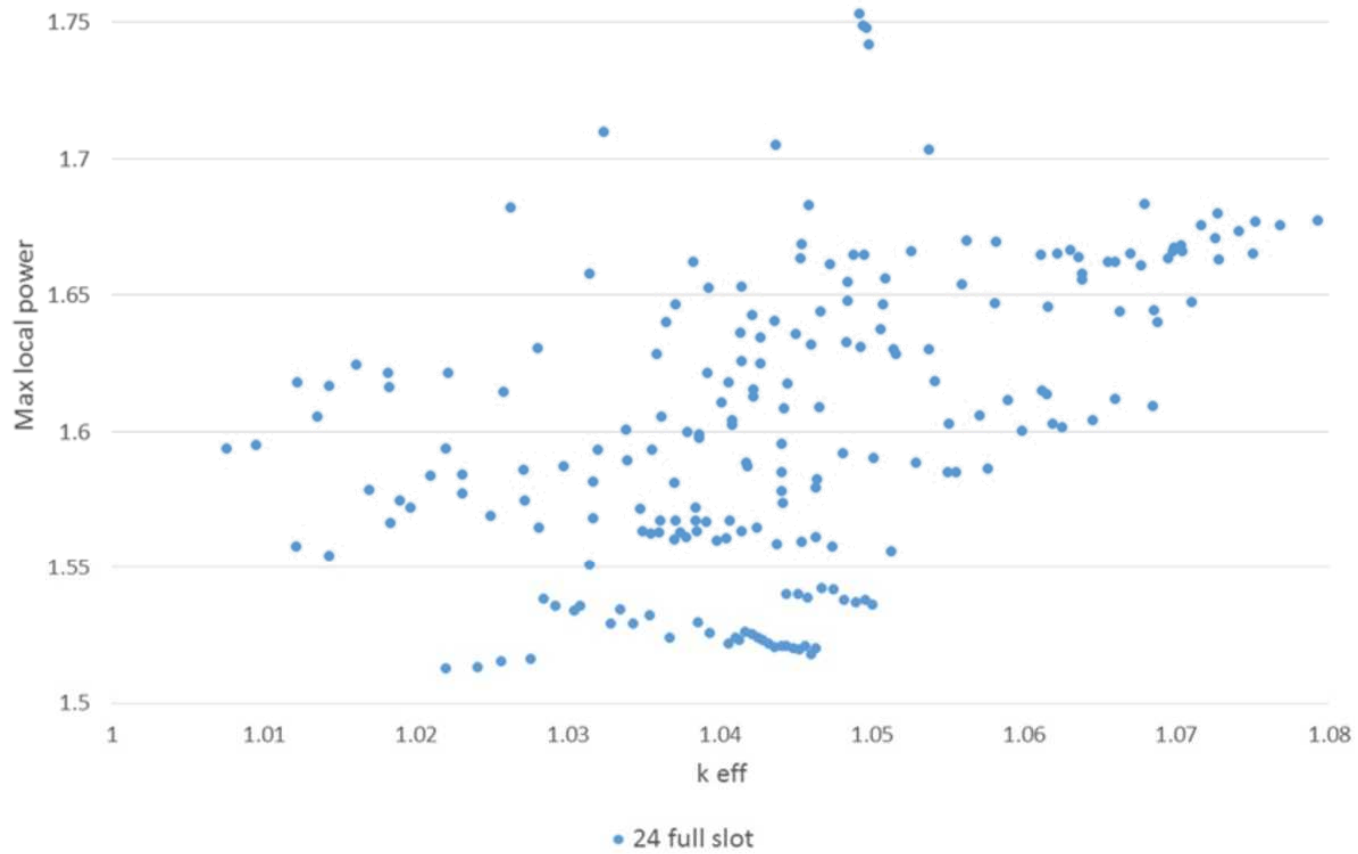

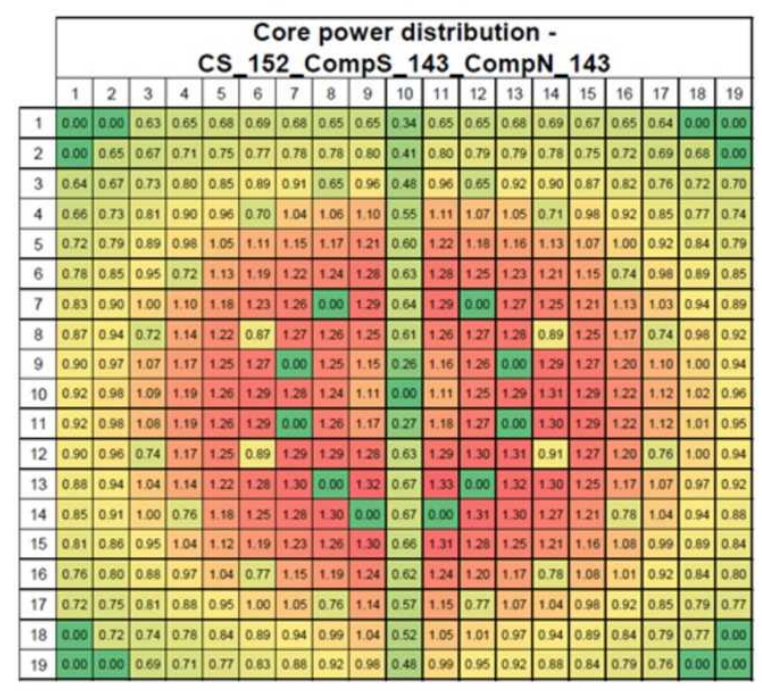

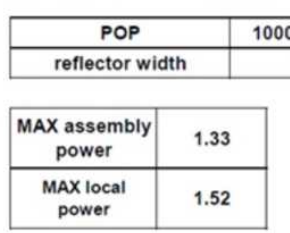

\begin{tabular}{|c|c|c|c|c|c|c|c|c|}
\hline $\begin{array}{l}\text { Rod positions } \\
\text { (in Serpent) }\end{array}$ & C/S & 152.57 & $\begin{array}{l}\text { Comp } \\
\text { South }\end{array}$ & 143.69 & $\begin{array}{l}\text { Comp } \\
\text { North }\end{array}$ & 143.69 & Trans & 98.05 \\
\hline \multicolumn{2}{|l|}{ how $n$} & \begin{tabular}{|c|}
.22 .01 \\
\end{tabular} & & \begin{tabular}{|l|}
13.13 \\
\end{tabular} & & \begin{tabular}{|l|l|}
-13.13 \\
\end{tabular} & & .1 .47 \\
\hline
\end{tabular}
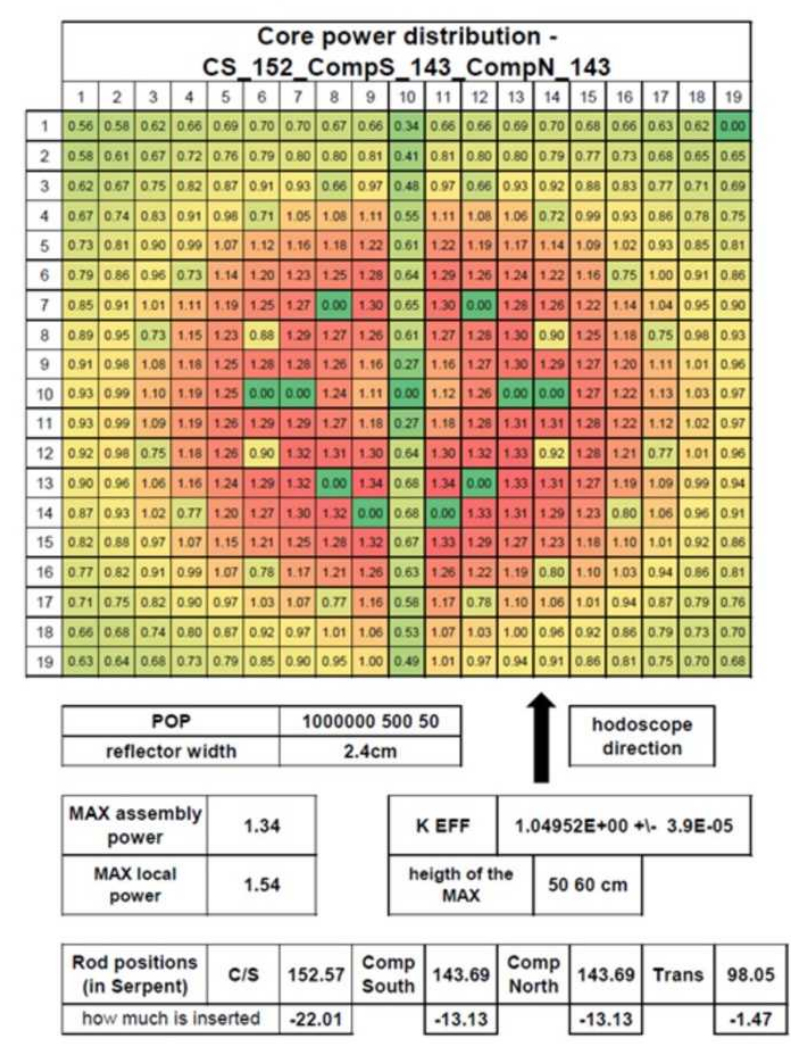

Fig. 22. 24-in. Full-Slot Core - Example Results. 


\section{no hodoscope core results}

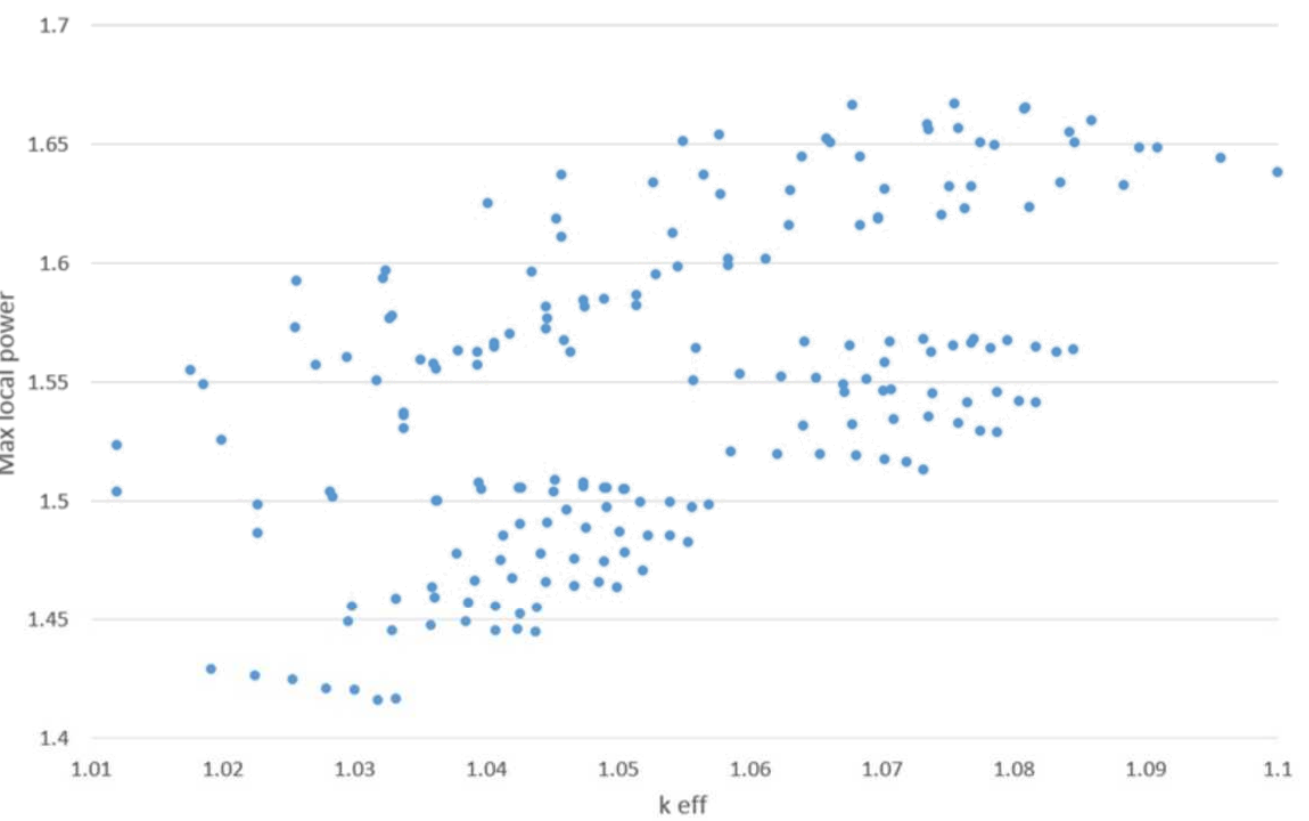

- no hodoscope

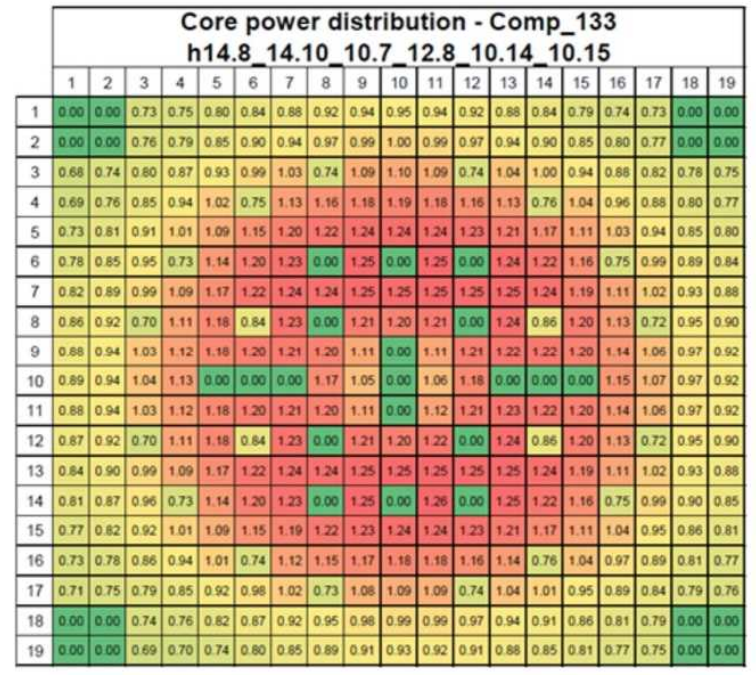

\begin{tabular}{|c|c|c|c|c|c|c|c|c|}
\hline \multicolumn{2}{|l|}{ POP } & \multicolumn{3}{|c|}{100000050050} & & \multirow{2}{*}{\multicolumn{2}{|c|}{$\begin{array}{l}\text { hodoscope } \\
\text { direction }\end{array}$}} & \\
\hline \multicolumn{2}{|c|}{ reflector width } & \multicolumn{3}{|c|}{$\cdot$} & & & & \\
\hline $\begin{array}{c}\text { MAX assembly } \\
\text { power }\end{array}$ & \multicolumn{2}{|c|}{1.26} & & KEFF & \multicolumn{4}{|c|}{$1.04379 E+00+1 \cdot 3.7 E-05$} \\
\hline $\begin{array}{l}\text { MAX local } \\
\text { power }\end{array}$ & \multicolumn{2}{|c|}{1.45} & \multicolumn{2}{|c|}{$\begin{array}{l}\text { heigth of the } \\
\text { MAX }\end{array}$} & \multicolumn{2}{|c|}{$5060 \mathrm{~cm}$} & & \\
\hline $\begin{array}{c}\text { Rod positions } \\
\text { (in Serpent) }\end{array}$ & c/s & 142.57 & $\begin{array}{l}\text { Comp } \\
\text { South }\end{array}$ & 133.69 & $\begin{array}{l}\text { Comp } \\
\text { North }\end{array}$ & 133.69 & Trans & 98.05 \\
\hline \multicolumn{2}{|c|}{ how much is inserted } & -12.01 & & -3.13 & & -3.13 & & -1.47 \\
\hline
\end{tabular}

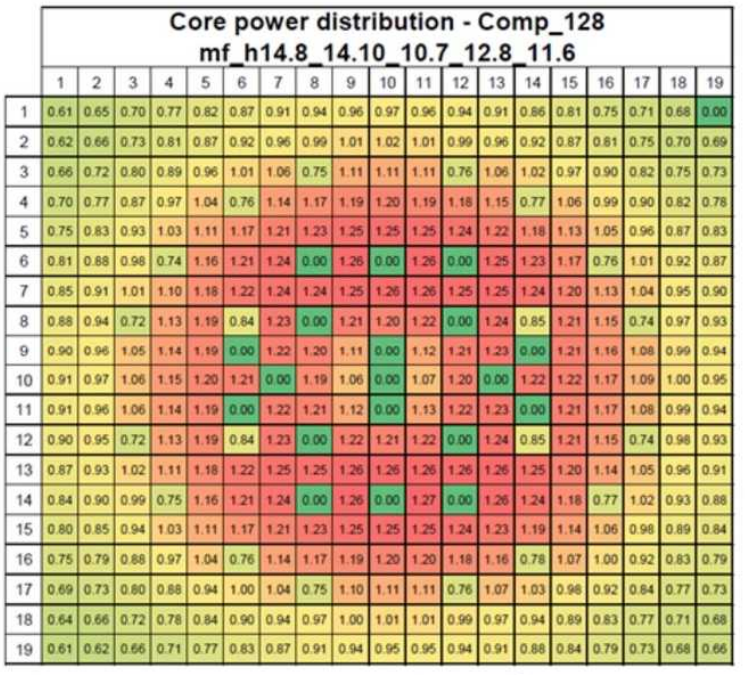

\begin{tabular}{|c|c|c|c|c|c|c|c|c|}
\hline \multicolumn{2}{|l|}{ POP } & \multicolumn{3}{|c|}{100000050050} & & \multirow{2}{*}{\multicolumn{2}{|c|}{$\begin{array}{l}\text { hodoscope } \\
\text { direction }\end{array}$}} & \\
\hline \multicolumn{2}{|c|}{ reflector width } & \multicolumn{3}{|c|}{$\cdot$} & & & & \\
\hline $\begin{array}{c}\text { MAX assembly } \\
\text { power }\end{array}$ & \multicolumn{2}{|c|}{1.27} & \multicolumn{2}{|c|}{ KEFF } & \multicolumn{4}{|c|}{$1.04853 \mathrm{E}+00+1 \cdot 4.0 \mathrm{E}-05$} \\
\hline $\begin{array}{l}\text { MAX local } \\
\text { power }\end{array}$ & \multicolumn{2}{|c|}{1.47} & \multicolumn{3}{|c|}{$\begin{array}{l}\text { heigth of the } \\
\text { MAX }\end{array}$} & $5060 \mathrm{~cm}$ & & \\
\hline $\begin{array}{l}\text { Rod positions } \\
\text { (in Serpent) }\end{array}$ & c/s & 142.57 & $\begin{array}{l}\text { Comp } \\
\text { South }\end{array}$ & 128.69 & $\begin{array}{l}\text { Comp } \\
\text { North }\end{array}$ & 128.69 & Trans & 98.05 \\
\hline \multicolumn{2}{|c|}{ how much is inserted } & -12.01 & & 1.87 & & 1.87 & & -1.47 \\
\hline
\end{tabular}

Fig. 23. Core without Hodoscope Slot - Example Results. 


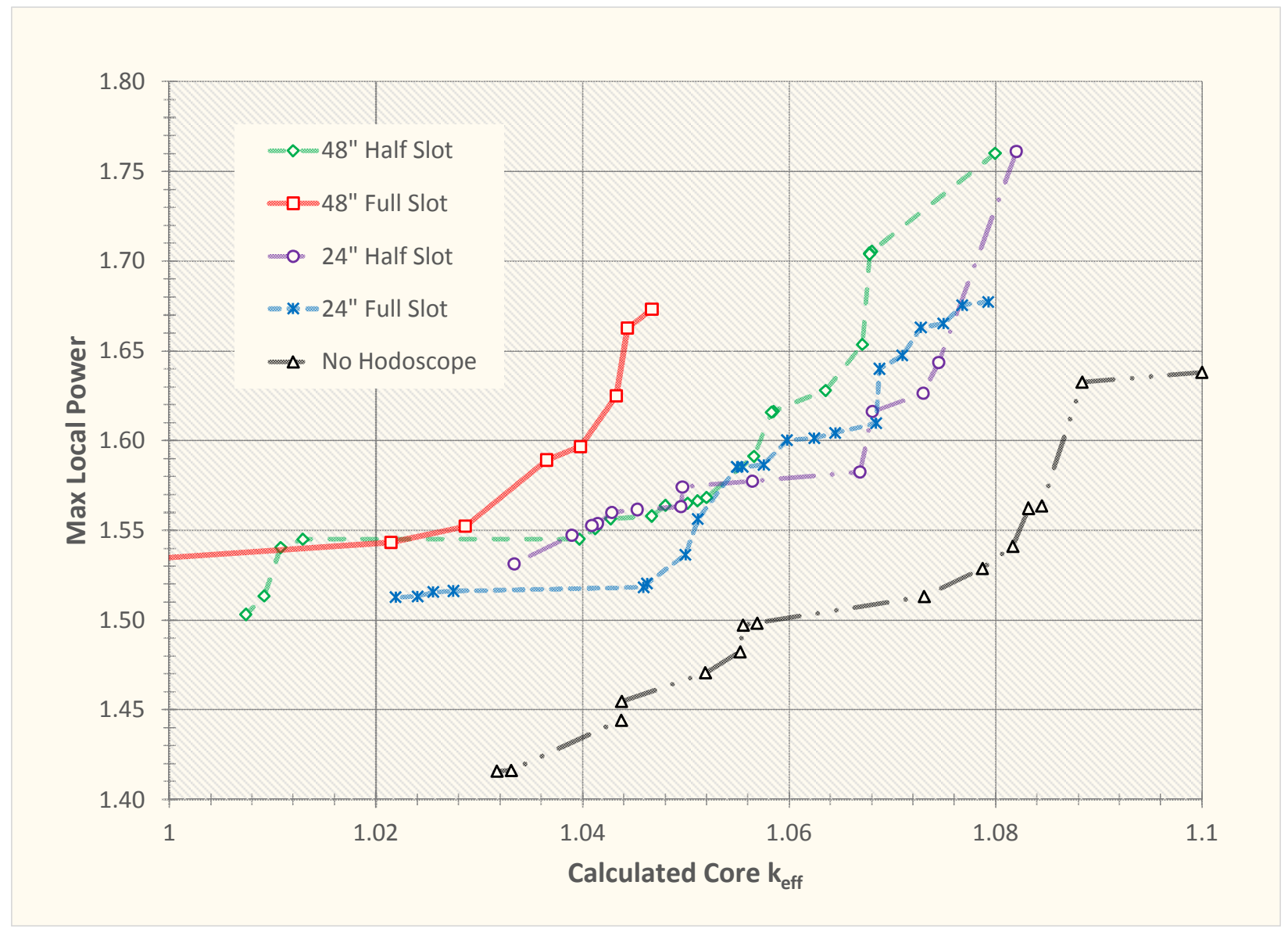

Fig. 24. Refined Core Assembly Management Boosts Available Excess Reactivity. Greater core reactivity allows for shorter pulse widths when coupled with enhanced clipping techniques. Minimization of localized assembly power is possible for configurations above and to the left of the generated boundary curves. 


\subsection{Fast Clipping System Concepts and Design}

As shown in Section 2.1, a minor facility modification to increase transient hydraulic drive pressure to roughly double the estimated transient rod speed from $140 \mathrm{in} . / \mathrm{s}(3.556 \mathrm{~m} / \mathrm{s})$ to $250 \mathrm{in.} / \mathrm{s}(6.35 \mathrm{~m} / \mathrm{s})$ would produce a desirable effect. Combined with the ability to initiate transients with larger steps, it is estimated that TREAT could reach BWR-like pulse widths with relatively minor modifications. These modifications would primarily entail taking credit for existing capabilities currently innate to the TREAT facility, and are recommended as near-term incremental improvements. However, the efforts undertaken in the first year of this project also demonstrate the need for a more marked capability enhancement in order to access the relevant pulse width range for PWR HZP-RIA. This capability would be impactful owing to the predominance of PWR-type plants in today's nuclear industry. As shown previously, enhanced clipping capabilities were found to be the most effective method of minimizing TREAT's pulse width. This finding is consistent with historic concepts that were conceptualized, but never realized, for the same purpose in TREAT (Crawford, et al., 1998 and Marshall 1989). Based on this historic concept, a design target of $-5 \% \Delta \mathrm{k} / \mathrm{k}$ in $5 \mathrm{~ms}$ was set. Several concepts for creating such a system were conceptualized and evaluated, ultimately resulting in concept prioritization for further development as summarized below.

A concept was evaluated consisting of modified dummy TREAT fuel assemblies, placed in high reactivity worth positions in the core, where a cavity would guide a rapidly-accelerated poison tube into the core. Using headroom above the active core, an integral pressure chamber would be charged with high pressure gas before the transient. Akin to a pneumatic actuator, a piston atop the poison tube would be mechanically released (likely by pyrotechnic fasteners) driving the poison in from the top of the core very rapidly. The rod would make use of ${ }^{10} \mathrm{~B}-$ 
enriched $\mathrm{B}_{4} \mathrm{C}$-dispersed-in-aluminum composite aluminum-clad plates in box-like square tube shape in order to give the maximum reactivity worth per accelerated mass $(\sim 2 \mathrm{~kg}$ per poison tube). Depending on the size of the poison tube, Monte-Carlo simulations suggested that two to four such assemblies would be needed to give the desired $-5 \% \Delta \mathrm{k} / \mathrm{k}$. Basic kinematic equations suggested that a pressure chamber small enough to fit within existing TREAT handling casks, pre-charged at $\sim 15 \mathrm{MPa}$, could drive the tube at speeds of $\sim 200 \mathrm{~m} / \mathrm{s}$ ( $\sim 8000 \mathrm{in} . / \mathrm{s})$. While not supersonic, this velocity would create a projectile with high kinetic energy. Naturally, decelerating the poison tube became the primary design concern with this concept which eventually became known as the "borated javelin launcher" (see Fig. 25). Corrugated-metal crushable shock absorbers were viewed as a viable method, but the one-time-use nature of the pyrotechnic fasteners and shock absorbers suggested an operational strategy where the entire clipping assemblies would need to be extracted from the core and refurbished after each use. While the borated javelin launcher concept likely remains a viable concept, it was deprioritized for these reasons. 


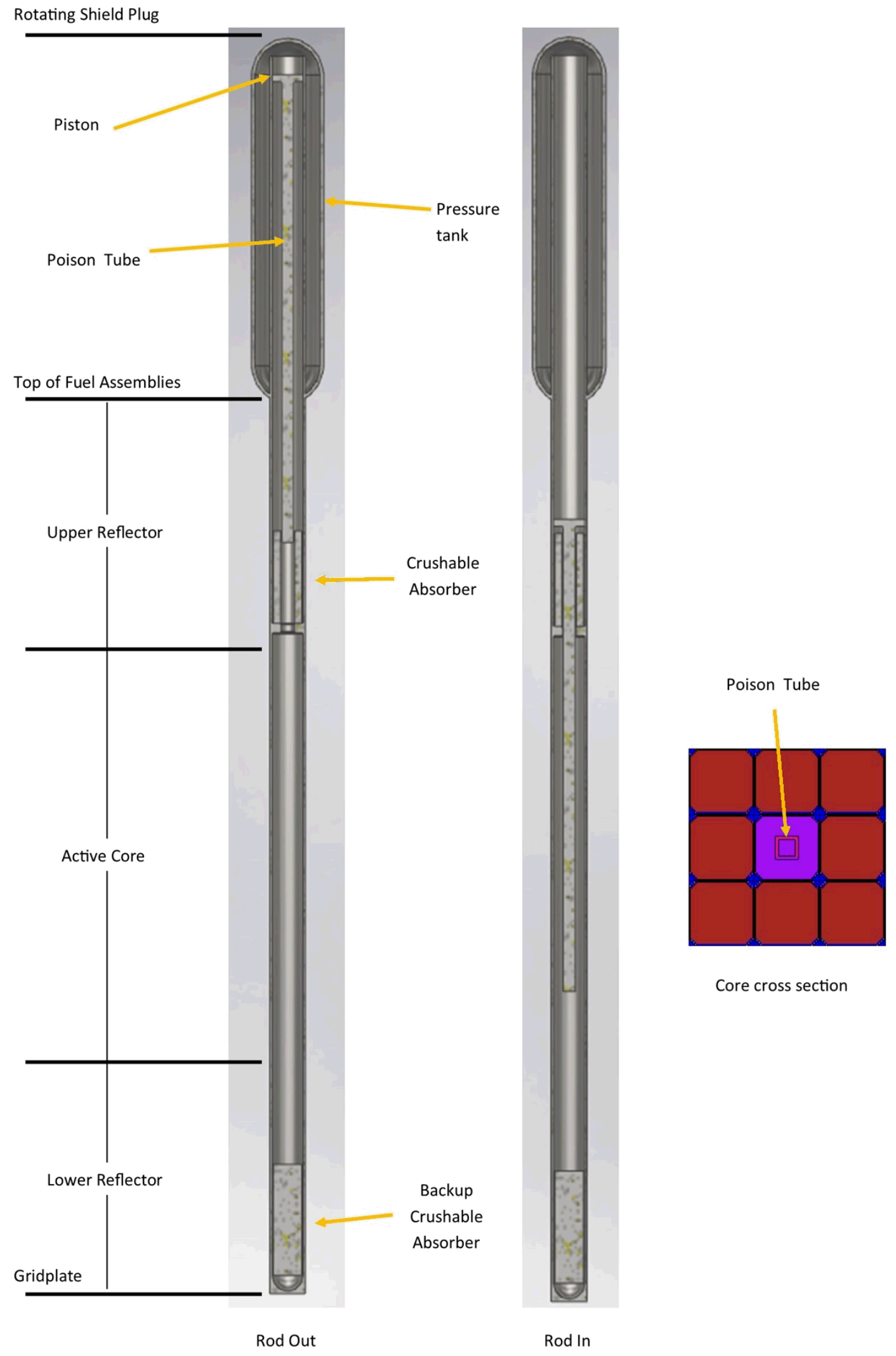

Fig. 25. Overview of the Borated Javelin Concept. 
Historic concepts for fast pulse termination suggested that a simple system, comprised of in-core evacuated chamber(s) prior to the transient, connected to out-of-core pressurized gas driver $\operatorname{tank}(\mathrm{s})$, could be used to inject neutron poison gas by means of precisely-timed fast-acting valves. Inadequate engineering design detail was available for historically-proposed TREAT designs (see Fig. 26), but all proposed to use ${ }^{3} \mathrm{He}$ (Crawford, et al., 1998). While such a system was never built for TREAT, a similar system was constructed and tested successfully at a Russian RBMK critical facility (Kachanov, et al., 2013). The CABRI reactor is outfitted with a similar ${ }^{3} \mathrm{He}$ system (Clamens, et al., 2016) and international collaboration with CABRI's experts can facilitate mechanical design with fast-acting valves, extremely leak-tight fittings, posttransient ${ }^{3} \mathrm{He}$ recovery, system modeling, and removal of contaminant gases from the system.

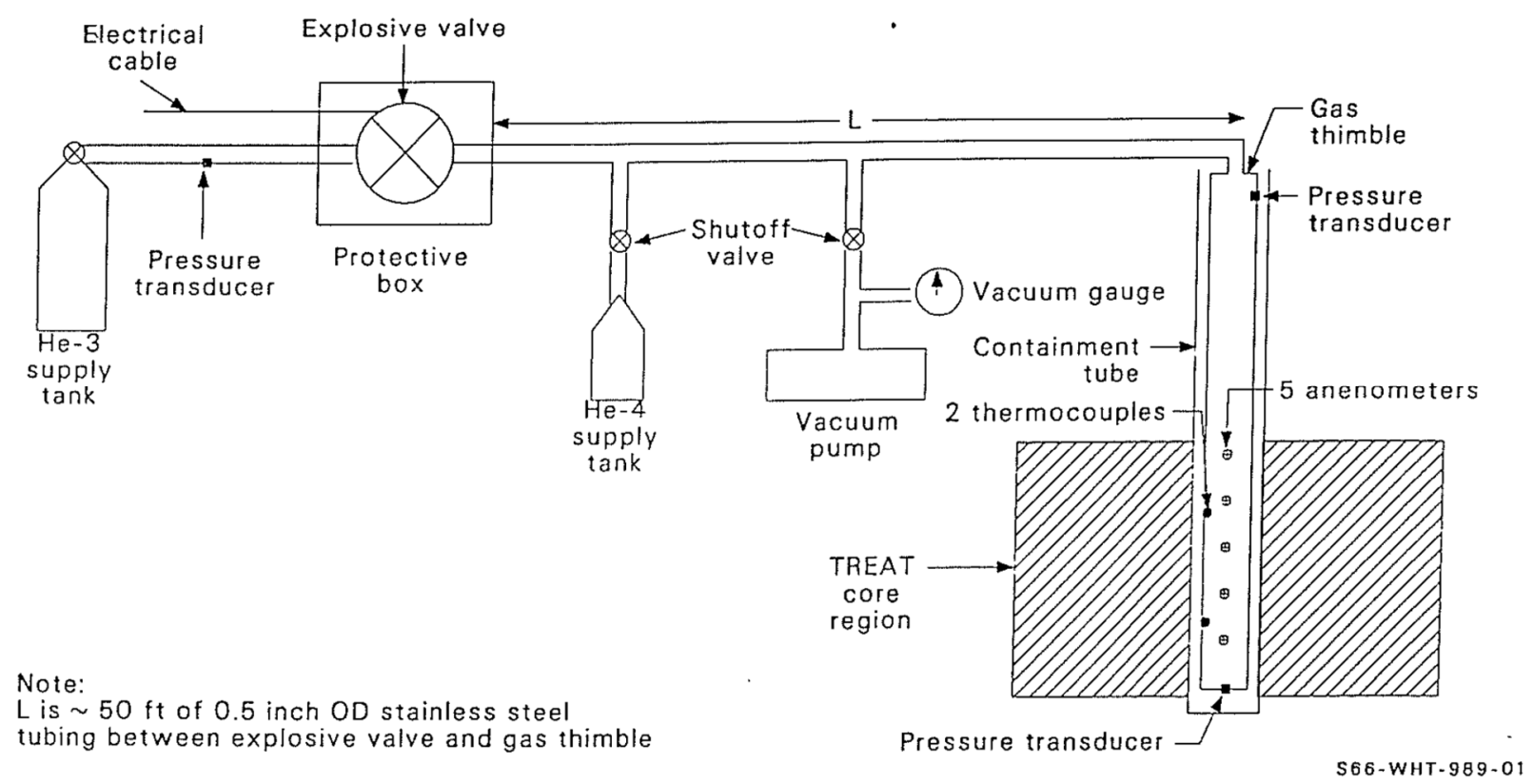

Fig. 26. Historic Concept of ${ }^{3} \mathrm{He}$ Injection in TREAT (Marshall 1989). 
An idea for the in-core gas chambers was conceptualized based on replacing TREAT fuel assemblies with zirconium-alloy tubes in a graphite-surrounded dummy assembly (see Fig. 27). Nuclear grade zirconium alloy $\mathrm{Zr}-2.5 \mathrm{Nb}$ was tentatively selected based on its reasonable strength at TREAT operating temperature conditions and neutron transparency. The final design of such a system may need to consider other alloy options based on detailed mechanical design considerations. Monte Carlo calculations indicated that two or three of these dummy assemblies, each with four gas chamber tubes (as shown in Fig. 28), could provide the desired pulse clipping capability if they could be pressurized with ${ }^{3} \mathrm{He}$ gas to $\sim 1-3 \mathrm{MPa}$ in $\sim 5 \mathrm{~ms}$. Although not designed in detail, vacuum pumps, compressors, and series of valves would be necessary to "reset" the system after each use. 

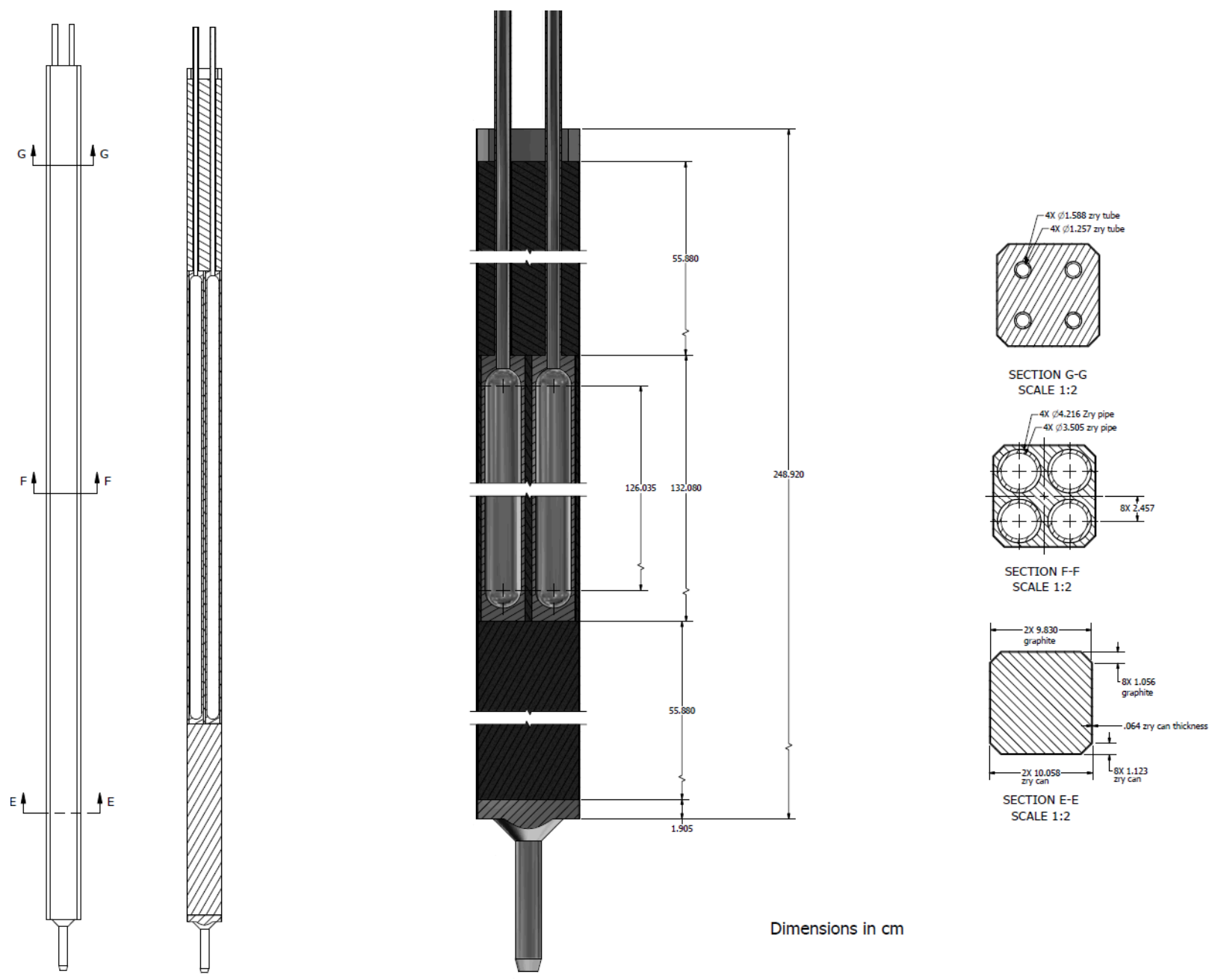

Fig. 27. Conceptual Mechanical Layout for ${ }^{3} \mathrm{He}$ Dummy Assemblies. 


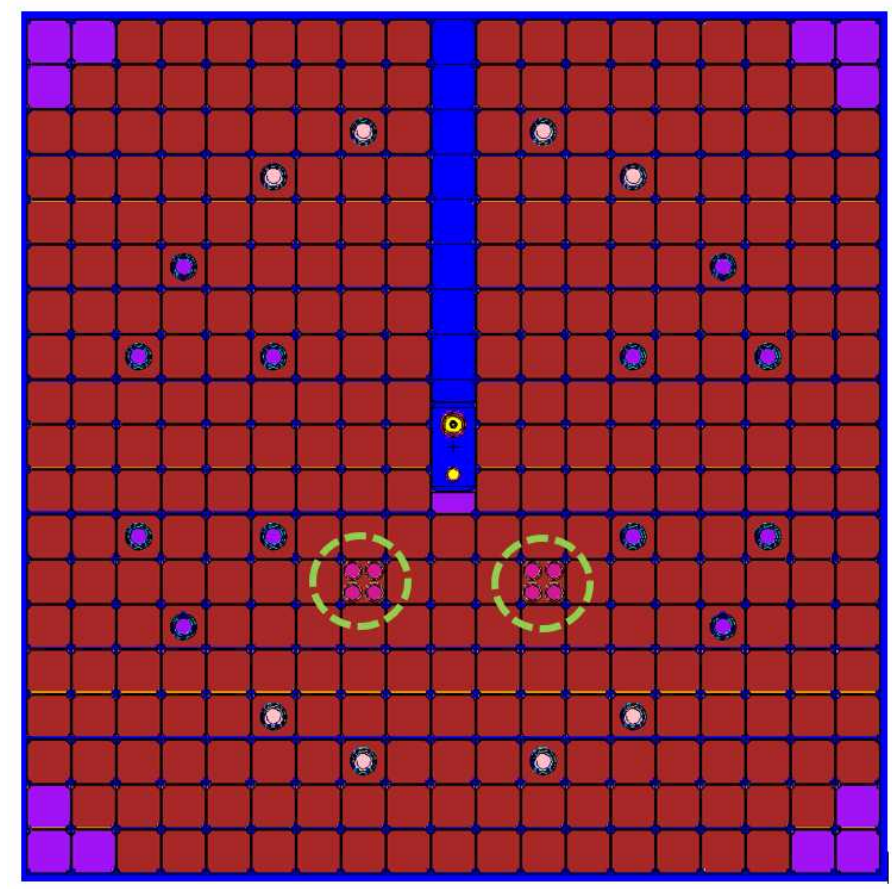

Fig. 28. ${ }^{3} \mathrm{He}$ Dummy Assembly Locations in Monte-Carlo Model.

While such a system is quite simple in its approach, it is constrained by two major factors: 1) the speed and repeatability of the valves and 2) the scarcity and cost of ${ }^{3} \mathrm{He}$. The first consideration can be addressed with the use of explosive valves, although reusable fast-acting solenoid valves would be more ideal for operational considerations, if viable. The scarcity of ${ }^{3} \mathrm{He}$, however, is a major consideration for such a system. Helium-3 does not naturally occur in any abundance on earth and must be artificially created. Helium-3 is a remarkable thermal neutron absorber with applications in detectors, neutron beams, and fusion sciences. Helium-3 in the United States is administered by the Department of Energy Isotope Program and, depending on a number of factors, is estimated to cost $\sim 1000 \$ / \mathrm{L}$ for government research users. As such, efforts were undertaken to determine whether an alternate poison gas would be viable.

${ }^{10} \mathrm{~B}$-enriched boron gas compounds were evaluated. Borane compounds were omitted from further consideration based on their relatively low condensation temperatures. Boron 
triflouride and trichloride, however, are commercially available with ${ }^{10} \mathrm{~B}$-enriched isotopic composition and provide comparable performance to ${ }^{3} \mathrm{He}$. While ${ }^{10} \mathrm{BF}_{3}$ appeared to be a strong candidate from a performance viewpoint, its toxic nature if inhaled, and acid-forming reactions with airborne moisture were drawbacks. Considering the need for redundant containment structures (part of which would be within geometrically-limited core regions) to protect personnel and TREAT core materials limits what materials can be implemented within TREAT. No other viable neutron poison gases could be identified and, as a result, ${ }^{3} \mathrm{He}$ was prioritized as the ideal pending design option, and the total volume of gas required will be evaluated.

Very little ${ }^{3} \mathrm{He}$ is needed in the core to actually achieve the desired clipping effect, the but a sizeable quantity of ${ }^{3} \mathrm{He}$ is required to fill the driver $\operatorname{tank}(\mathrm{s})$. Hydraulic models of a system akin to that proposed historically (Marshall 1989), but capable of the desired $-5 \% \Delta \mathrm{k} / \mathrm{k}$ in $5 \mathrm{~ms}$, indicated the volume of the driver tank would yield an unacceptably expensive quantity of ${ }^{3} \mathrm{He}$. As a result, design parameters were investigated to determine what affected the quantity of ${ }^{3} \mathrm{He}$ the most, including geometry/quantity of the in-core chambers, volume/pressure of the driver

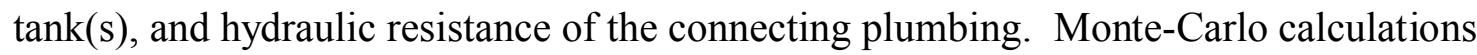
indicated that an annular in-core pressure chamber geometry (comprised of two concentric pipes in something akin to a TREAT dummy assembly) would provide the best combination of neutron-capturing "flux area", geometry viable for pressure vessel structural application, and highest reactivity worth per ${ }^{3} \mathrm{He}$ quantity owing to the minimized self-shielding in the ${ }^{3} \mathrm{He}$ region. Connection piping was minimized by placing a small driver tank atop the assembly above the core, but below the rotating shield plug. Textbook gas flow calculations showed that this system could achieve the pressure needed for effective clipping with a total ${ }^{3} \mathrm{He}$ volume at least an order-of-magnitude less than the initial design concept. 
After use in a single clipped transient, plumbing connections atop the assembly would be connected to an auxiliary system to reset the system for subsequent use. An enabling assumption for this design was the existence of a suitably small and fast-acting valve, but detailed valve investigations have not yet been completed. Ideally this valve would be reusable (i.e. not an explosive valve), with extraction of the entire assembly from the core for valve replacement after each use (see Fig. 29). This ${ }^{3} \mathrm{He}$ optimization scoping effort will be accomplished later under the LDRD project period via student collaboration. Detailed mechanical design work, gas dynamic modeling, and laboratory testing will be necessary to comprehensively explore this design. Based on these evaluations, a fast clipping system based around cartridge-type ${ }^{3} \mathrm{He}$-injection assemblies appears to be the strongest candidate concept to attain PWR HZP-RIA transients requirements, but other concepts may be evaluated as appropriate.

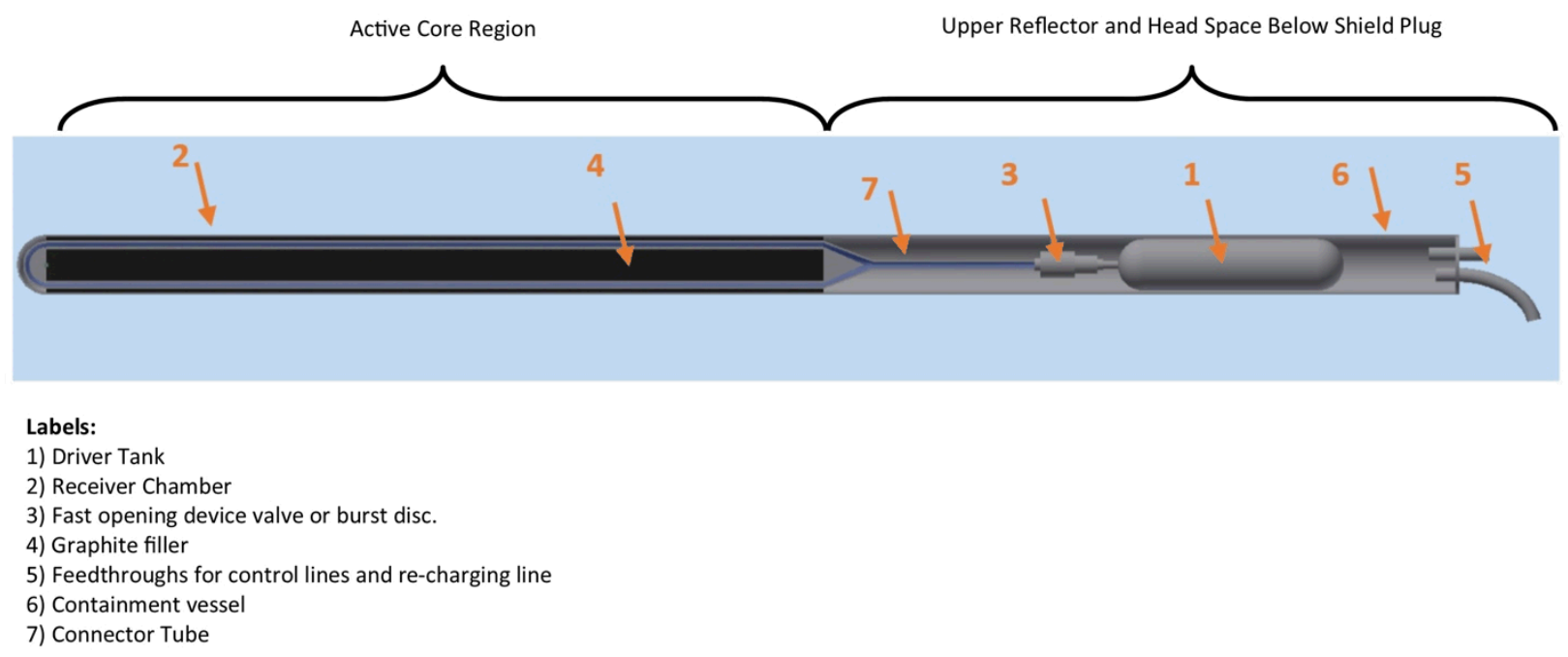

Fig. 29. Cartridge-Type ${ }^{3} \mathrm{He}$ System.

\section{Future Work}

Development of pulse width shortening capabilities in TREAT will enhance its ability to provide prototypic test environments for LWR fuels while not diminishing any of its current 
testing capabilities. This approach will be consistent with TREAT's flexible nature and ability to support multiple missions. These enhanced capabilities will lead to increased opportunities for future transient experimentation, post-transient experimentation, and advanced modeling and simulation of fuel behavior. Owing to the novel layout of the proposed ${ }^{3} \mathrm{He}$ injection system, difficulty in accurate modeling its necessary high-speed compressible gas flows, and need for special purpose components whose function must be empirically demonstrated (e.g. fast acting valves), future work will invest in the construction and testing of a lab scale prototype for model verification and component testing.

With TREAT having recently resumed full transient operations future work will be able to execute a series of transients which employ current transient control rods as the clipping system. While this effort is not expected to achieve dramatically-narrowed pulses compared to the ${ }^{3} \mathrm{He}$ injection option, these first-of-a-kind transient exhibitions will help quantify model biases for more accurate evaluation of enhanced clipping designs. This effort will also help determine whether incremental improvements to existing transient rod drive speeds are prudent for near term options with modest pulse width reduction. In concert with this effort, near future work will also develop, fabricate, and install new neutron poison assemblies in TREAT's core periphery. These poison assemblies will be precisely tuned and positioned so that adequate excess reactivity exists in the transient rods for large step insertions while reducing the core neutron lifetime for modest pulse reductions. A series of transient demonstrations will once again occur in TREAT with these incremental improvements in order to further verify kinetic models and quantify the pulse narrowing enhancements possible with ${ }^{3} \mathrm{He}$ clipping; thus, paving the way for selection of the enhanced clipping system's final parameter and its future deployment. 


\section{Conclusions}

While TREAT's flexible design and multi-mission nature saw historic experiments for numerous reactor fuels and transient types, it was never specifically adapted to address very-brief pulse transients akin to postulated LWR RIAs. Kinetic models of TREAT were exercised to determine which nuclear parameters most affected pulse duration. These investigations showed incremental improvements for minor facility enhancements including increased reactivity step insertions (to initiate the power pulse) and slightly-increased transient rod drive speed for pulse termination (“clipping") via uprated rod drive system pressure. Modern nuclear models demonstrated three-dimensional computational tools can be used to optimize the core power peaking profile to permit increased reactivity step insertions. By replacing peak fuel assemblies with graphite dummy or hodoscope assemblies, fixing TREAT's various non-transient control rods at deliberate positions to hold down the "hot side" of the core, and balancing against the required excess reactivity needed in the transient rods, the limiting fuel assembly power can be reduced on the order of $\sim 20 \%$. This is a remarkable discovery of latent capability in the TREAT facility, not only in enabling the subject capabilities for reduced pulse widths, but also for uprating the core's transient energy capacity by a significant amount.

While incremental improvements can likely enhance TREAT's capability into BWRrelevant missions, the aforementioned kinetic models also demonstrated that the briefer PWR pulse shapes can only be achieved with a yet-to-be-designed advanced clipping system. Several enhanced clipping concepts were explored including pneumatically-driven light weight clipping rods and neutron poison gas injection into in-core chambers. For a number of engineering reasons, the gas injection concepts were prioritized for further development. Several viable poison gases were evaluated for nuclear affects and design considerations. Helium-3 was found 
to offer the greatest benefits for clipping design and overall performance. Pending future evaluations of crucial design components, such as fast-acting valves, this design concept will likely become the focal point of future work under this LDRD to lay the foundation for its ultimate deployment at TREAT.

This project will develop the information needed to deploy a set of capabilities which are crucial in enabling TREAT to adequately address a major component of nuclear safety research in direct support of the most prevalent reactor types in the industry. The pulse-narrowing strategy is not yet mature enough to perform detailed resource level and deployment timing evaluations at this point in the project, but it is reasonable to expect that this capability will be impactful for Department of Energy Office of Nuclear Energy (DOE-NE) programs such as the ATF campaign. This capability will also be crucial for industrial partners to resolve data gaps in performance of state-of-the-art fuels benefitting greatly from accident testing capabilities which faithfully represent the postulated conditions to establish license-supporting safety tests.

\section{Acknowledgments}

This research made use of the resources of the High-Performance Computing Center (HPC) at Idaho National Laboratory (INL), which is supported by the Office of Nuclear Energy of the U.S. Department of Energy (US DOE-NE) and the Nuclear Science User Facilities (NSUF); this work was supported through the INL Laboratory Directed Research and Development (LDRD) Program (No. 17A1-024FP) under the DOE Idaho Operations Office under Contract No. DE-AC07-05ID14517.

\section{References}


N. E. Woolstenhulme, J. D. Bess, C. B. Davis, L. M. Dusanter, C. P. Folsom, J. R. Parry, T. H. Shorthill, H. Zhao, “Optimization Options for Narrowing Transient Testing Pulse Widths Necessary to Enhance LWR RIA Simulations in the TREAT Facility," Proc. PHYSOR 2018, Cancun, Mexico (22-26 April 2018).

G. A. Freund, H. P. Iskendarian, and D. Okrent, “TREAT, a Pulsed Graphite-Moderated Reactor for Kinetics Experiments," Proc. $2^{\text {nd }}$ United Nations Int. Conf. on the Peaceful Uses of Atomic Energy, Geneva, Switzerland, 10, 461 (1958).

A. E. Wright, "Transient Testing of Nuclear Fuels in TREAT: An Overview," Trans. Am. Nucl. Soc., 112, 352 (2015).

J. Bumgardner, "Status of the TREAT Reactor Restart and the Resumption of Transient Testing," Trans. Am. Nucl. Soc., 112, 350 (2015).

N. E. Woolstenhulme, D. M. Wachs, and A. B. Beasley, “Transient Experiment Design for Accident Tolerant Fuels," Trans. Am. Nucl. Soc., 111, 604 (2014).

A. De Volpi, et al., "Fast-Neutron Hodoscope at TREAT: Methods for Quantitative Determination of Fuel Dispersal," Nucl. Technol., 56, 141 (1982).

D. L. Chichester, et al., "The TREAT Fast-Neutron Hodoscope and Plans for Restoring it to Operation," Trans. Am. Nucl. Soc., 112, 377 (2015).

“TREAT Baseline Description Document,” ANL/RAS-72-73, Argonne National Laboratory (1972).

J. D. Bess and M. D. DeHart, "Baseline Assessment of TREAT for Modeling and Analysis Needs," INL/EXT-15-35372, Idaho National Laboratory (2015).

D. R. MacFarlane, G. A. Freund, J. F. Boland, "Hazards Summary Report on the Transient Reactor Test Facility (TREAT),” ANL-5923, Argonne National Laboratory (1958). 
N. E. Woolstenhulme, J. D. Bess, C. B. Davis, G. K. Housley, C. B. Jensen, R. C. O’Brien, D. M. Wachs, “TREAT Irradiation Vehicle Designs, Capabilities, and Future Plans,” Proc. PHYSOR 2016, Sun Valley, ID (1-5 May 2016a).

M. D. DeHart, et al., "Research in Support of TREAT Kinetics Calculations Using Rattlesnake/BISON Coupling within MAMMOTH," Proc. PHYSOR 2016, Sun Valley, ID (1-5 May 2016).

S. B. Grover, D. A. Petti, J. T. Maki, “Completion of the First NGNP Advanced Gas Reactor Fuel Irradiation Experiment, AGR-1, in the Advanced Test Reactor, Proc. HTR 2010, Prague, Czech Republic (18-20 October 2010).

D. L. Knudson, J. L. Rempe, “Linear Variable Differential Transformer (LVDT)-Based Elongation Measurements in Advanced Test Reactor High Temperature Irradiation Testing, Meas. Sci. Technol., 23, 025604 (2012).

P. A. Demkowicz, D. V. Laug, D. M. Scates, E. L. Reber, L. G. Roybal, J. B. Walter, J. M. Harp, R. N. Morris, “The Fuel Accident Condition Simulator (FACS) Furnace System for High Temperature Performance Testing of VHTR Fuel," Nuc. Eng. Des., 251, 164 (2012).

W. R. Robinson and T. H. Bauer, "Power Coupling in TREAT M-Series: New Experimental Results from M7CAL and Updated Analyses," ANL-IFR-86, Argonne National Laboratory (1988).

W. R. Robinson and T. H. Bauer, "The M8 Power Calibration Experiment (M8CAL)," ANLIFR-232, Argonne National Laboratory (1994).

“Technical Specifications for the TREAT Facility," TS-420, Idaho National Laboratory (2017). “Transient Reactor Test (TREAT) Facility FSAR,” SAR-420, Idaho National Laboratory (2017). 
J. Carmack, F. Goldner, S. M. Bragg-Sitton, L. L. Snead, "Overview of the U.S. DOE Accident Tolerant Fuel Development Program," Proc. Top Fuel 2013, Charlotte, NC (15-19 September 2013).

C. P. Folsom, C. B. Jensen, R. L. Williamson, N. E. Woolstenhulme, H. Ban, D. M. Wachs, "BISON Modeling of Reactivity-Initiated Accident Experiments in a Static Environment," Proc. Top Fuel 2016, Boise, ID (11-15 September 2016).

E. Yang, "Topical Report on Reactivity Initiated Accident: Bases for RIA Fuel and Core Coolability Criteria,” EPRI Technical Report 1002865, EPRI, Palo Alto, CA (2002).

J-C. Cabrillat, M. Maegey, D. Bourguignon, G. Miachon, F. Forestier, J-P. Coulon, M. Faury, "The CABRI Facility: Implementation of a Pressurized Water Loop and Related Safety Review," Proc. IGORR 9, Sydney, Australia (24-28 March 2003).

T. Fuketa, T. Sugiyama, F. Nagase, "Behavior of 60 to $78 \mathrm{MWd} / \mathrm{kgU}$ PWR Fuels under Reactivity-Initiated Accident Conditions,” J. Nucl. Sci. Technol., 43, 1080 (2006).

P. Royl, W. Breitung, E. A. Fischer, G. Schumacher, R. O. Gauntt, S. A. Wright, “Contributions from the ACRR In-Pile Experiments to the Understanding of Key Phenomena Influencing Unprotected Loss of Flow Accident Simulations in LMFBRs," Nucl. Eng. Des., 100, 387 (1987).

F. Payot, F. Serre, A. Bassi, C. Suteau, E. Batyrbekov, A. Vurim, A. Pakhnits, V. Vityuk, "The SAIGA Experimental Program to Support the ASTRID Core Assessment in Severe Accident Conditions," Proc. FR17, IAEA-CN245-067, Yekaterinburg, Russia (26-29 June 2017).

D. A. Petti, R. R. Hobbins, D. L. Hagrman, “The Composition of Aerosols Generated During a Severe Reactor Accident: Experimental Results from the Power Burst Facility Severe Fuel Damage Test 1-4,” Nucl. Technol., 105, 334 (1994). 
J-P. Hudelot, E. Fontenay, C. Molin, A. Moreau, L. Pantera, J. Lecerf, Y. Garnier, B. Duc, "CABRI Facility: Upgrade, Refurbishment, Recommissioning and Experimental Capacities," Proc. PHYSOR 2016, Sun Valley, ID (1-5 May 2016).

N. E. Woolstenhulme, et al., "Capabilities Development for Transient Testing of Advanced Nuclear Fuels at TREAT," Proc. Top Fuel 2016, Boise, ID (11-16 September 2016b).

O. Clamens, J. Lecerf, B. Duc, J-P. Hudelot, :Assessment of the CABRI Transients Power Shape by using CFD and Point Kinetics Codes," Proc. PHYSOR 2016, Sun Valley, ID (1-5 May 2016). D. C. Crawford, A. E. Wright, R. W. Swanson, R. E. Holtz, "RIA Testing Capability of the Transient Reactor Test Facility," Proc. IAEA Tech. Comm. Mtg. on Fuel Cycle Options for LWRs and HWRs, IAEA-TECDOC-1122, pp. 99-102, Victoria, Canada, (May 1998).

"Nuclear Fuel Behaviour under Reactivity-Initiated Accident (RIA) Conditions, State-of-the-Art Report,” NEA/CSNI/R(2010)1, OECD NEA, Paris, France (2010).

RELAP5-3D Code Manual, Volumes I-V, Rev. 4.4, INL/MIS-15-36723, Idaho National Laboratory (2018).

C. B. Davis, "Development and Validation of a RELAP5-3D Point Kinetics Model of TREAT," ECAR-3458, Idaho National Laboratory (2016).

J. D. Bess, et al., "Core Power Flattening Studies Supporting Narrowing Transient Pulse Widths in TREAT," Trans. Am. Nucl. Soc., 118, 997 (2018).

J. Leppanen, et al., "The Serpent Monte Carlo code: Status, development and applications in 2013," Ann. Nucl. Energy, 82, 142 (2015).

M. B. Chadwick, et al., "ENDF/B-VII.1 Nuclear Data for Science and Technology: Cross Sections, Covariances, Fission Produce Yields and Decay Data," Nucl. Data Sheets, 112, 2887 (2011). 
Letter from R. W. Marshall to L. J. Harrison, "Request for Technical Feasibility Evaluation of the Fast Shutdown System Verification Tests," RWN-11-89, Idaho National Laboratory (22 September 1989).

V. Kachanoc, E. Burlakov, A. Kuzmin, V. Jitarev, "Experiment for Substantiation of RBMK Fast-Scram System Based on Gaseous Absorber," Proc. ICNC 2003, JAERI-CONF 2003-019, pp. 221-224, Kashiwa, Japan (2013). 